\title{
Winter surface salinity in the northeastern Gulf of Maine from five years of SMAP satellite data
}

\author{
Grodsky Semyon A. ${ }^{1,}{ }^{*}$, Vandemark Douglas ${ }^{2}$, Reul Nicolas ${ }^{3}$, Feng Hui ${ }^{2}$, Levin Julia 4
}

1 Department of Atmospheric and Oceanic Science, University of Maryland, College Park, USA

2 University of New Hampshire, Durham, USA

3 IFREMER, University Brest, CNRS, IRD, Laboratoire d'Oceanographie Physique et Spatiale (LOPS), IUEM, Brest, France

${ }^{4}$ Rutgers University, New Brunswick, NJ, USA

* Corresponding author : Semyon A. Grodsky, email address : senya@atmos.umd.edu

\begin{abstract}
:
Wintertime freshwater transport into the Gulf of Maine (GoM) is typically controlled by a seasonal velocity increase in the fresh upstream Nova Scotia Current (NSC). Repeat satellite observations from the Soil Moisture Active Passive mission have mapped significant GoM surface salinity anomalies in four of five recent winters. These satellite data are used in combination with Jordan basin buoy and model datasets to investigate the likelihood that variable wind-forcing of the NSC contributed to these anomalies. This stems from regional ocean circulation studies suggesting that strengthening of alongshore southwesterly winds on the Scotian shelf weakens NSC transport into the GoM, while cross-shore southeasterly winds may also contribute to NSC weakening, and vice versa. A 17-year time series analysis of GoM buoy and satellite data shows that near-surface salinity in the eastern GoM can indeed be modulated by both alongshore and cross-shore winds through their impact on the NSC. The NSC geostrophic current modulation correlates with buoy-observed surface salinity anomalies when using a one month advective lead time. For a shorter 5-year period, a SMAP-derived salinity anomaly index in the eastern GoM indicates a similar relation to NSC variation and also correlates with Scotian Shelf wind anomalies. The relationships between winter wind and NSC transport variability are confirmed using output from a 19year high resolution global ocean simulation. Attribution of these local wind anomalies to basin-scale atmospheric patterns shows that most years with strong winter GoM freshening coincide with weakening of a North Atlantic Oscillation-like wind pattern. But its reversals do not always correspond with a saline GoM. This contrast suggests that wind forcing more directly controls fresh winter GoM anomalies but not salty. Instead, they are partly due to density-driven advection from neighboring warm and saline Atlantic slope water including episodic Gulf Stream instabilities.
\end{abstract}

\section{Highlights}

SMAP detects significant eastern GoM SSSA (up to $1 \mathrm{psu}$ ) in four of five winters. Jordan basin SSSA correlation with Nova Scotia Current geostrophic anomaly is $\sim 0.7$. Only half of the above correlation is explained by wind-driven current variations. Eastern GoM satellite SSSA index is better indicator of fresh Scotian Shelf inflows. 


\section{Introduction}

Gulf of Maine (GoM) salinity changes at interannual to decadal time scales are accompanied by biochemical shifts that can, along with changing temperature, ultimaı ${ }^{1} y$ impact water column stratification as well as the ecosystem across many trophic levels 'M.Gillicuddy et al., 2011; Mountain and Kane, 2010; Townsend, 1991; Runge et al., . 0.1. ' 'orz et al., 2019; Li et al., 2014). Detection and prediction of both thermohaline v arla 'suity and trends are topics of intense recent focus (Pershing et al., 2015; Hare et al., 2016). Thu study of the ocean circulation within the connected coastal Scotian Shelf, Bay of Fundy nc GoM systems has a rich history using both hydrographic data and models to $\operatorname{addr}^{r}$ is $\mathrm{ly}_{\mathbf{n}}{ }^{\top}$ mics that are largely defined by the complex bathymetry and coastline (for reviews, see T_vnsend et al., 2015; Loder et al., 1997). Yet there is still a lack of certainty regarding the me hanisms that control competing inflows to this marginal sea from offshore and from $\mathrm{th} \geqslant$; djoining upstream Nova Scotian Shelf. Investigation of these controls has considered ${ }^{c_{0}}$-ing that spans from local air-sea fluxes and tides to remote forcing via Arctic ice dynamics anc. atmospheric teleconnections (Greene et al., 2013; Mountain, 2012; Greene and Pershir o, ? v J). While the annual cycle of near-surface salinity in the Gulf of Maine and adjoining shc'ves Is well documented (cf. Mountain and Manning, 1994; Richaud et al., 2016; Bisagni, 2016, rurther data on interannual change are needed to clarify the strength of key advective-forcing mechanisms and how they may be used to monitor and model thermohaline variability. Several recent studies have used a combination of satellite altimetry and regional and satellite wind data (Li et al., 2014; Feng et al., 2016; Grodsky et al., 2017) to confirm the importance of regional wind forcing on the amount of Scotian Shelf water transport to the Gulf (Smith, 1983). One salient component of Gulf circulation is that cold freshwater inflow from the Scotian Shelf is greatest each winter, often freshening surface layers in the eastern Gulf of Maine. The new time series of region-wide surface salinity data provided by the SMAP (Soil Moisture Active Passive) satellite since 2015 leads one to ask - Can we use a 
complement of weekly-to-monthly satellite observations over the eastern Gulf of Maine winter to improve understanding about the drivers of interannual salinity change in the Gulf of Maine? This study assesses this question with observations spanning five recent winters.

The two major source waters for the GoM enter first into the eastern Gulf. These inputs are NW Atlantic slope sea waters and Scotian Shelf Water (SSW), with respective inflow via the Northeast channel (NEC) and along the shelf SW of Cape Sable, Nova Scotia (see Figure 1). NEC inflow primarily consists of Warm Slope water (WSW), and less frequently Labrador Slope Water (LSW), Gulf Stream meanders, or warm-core ring water (WCR). SSW enters as Cape

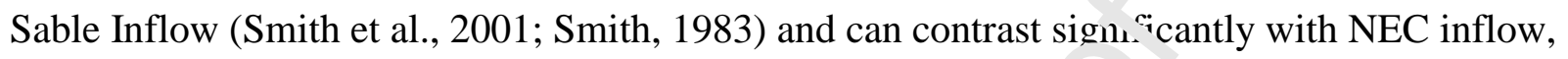
being significantly colder and fresher and with comparable trans $s_{1}$ ort variability. Until recently, the prevailing conceptual model for advective influence on $\mathrm{S}$ iff r f Maine water masses, nutrients, and biochemistry was focused on the NEC an $r$. $v$ rıbility, variation in its larger subsurface inflows due to wind (Ramp et al., 1985), anr c. observed differences between WSW and infrequent episodic LSW or warm-core ring in fl $\mathrm{J}$ s (e.g. Mountain, 2012; Brooks, 1987; Grodsky et al., 2018b). But recent analyses vi lo o-term continuous moored observations within the Gulf of Maine suggest that more focus s. uld be placed on observing and understanding the complex balance between NEC and Cape Sable Inflow (CSI) on interior Gulf of Maine water masses, both at the surface and for devrer rayers (Smith et al., 2012; Townsend et al., 2015). In particular, observations in the last . ecades at Jordan Basic Buoy M01 indicate an increased amount of fresh SSW in the $G_{\iota}{ }^{\prime} f$, resumably carried by the CSI from the Scotian Shelf, rather than through the NEC. Tr e e dies also emphasize the need to improve long-term monitoring of both NEC and CSI $1,{ }^{9}{ }_{0} \ldots$, and the factors that control them, particularly just upstream on the adjoining Scotian Shelf ( considered as factors modulating the Nova Scotia Current (NSC) and its delivery of SSW to the Gulf. A recognized limit of these buoy-focused investigations is the reliance on just two locations (station M and N, Townsend et al., 2015) within this fairly complex circulation, and with no ongoing measurements near the critical Cape Sable shelf.

In this new attempt to examine controls on upper ocean salinity in the Gulf of Maine we choose to focus on the eastern GoM, defined here to span roughly from Brown's Bank in the south to Jordan Basin to the north (see Figure 1). Mountain and Manning (1994) observed that the surface salinity in this region is distinct from the interior Gulf largely because it first receives 
water from the NEC and CSI, whereas advection and mixing from tides, winds, and local rivers lead to its decorrelation with surface salinity in the interior Gulf. This study will also focus on the winter period and spatially-mapped sea surface salinity anomalies (SSSA) observed in successive winters. Given this seasonal focus, the main control we seek to further assess is wind forcing and its resulting impact on local circulation and eastern Gulf of Maine surface salinity. The NSC and its characteristics on the SW Scotian shelf will thus be central to the investigation (see Smith, 1983; Smith et al., 2001; Smith et al., 2012; Han et al., 1997; Brickman et al., 2016). And while alongshore SSW impacts on the Gulf of Maine SSSA are a focus, it is also understood that there are many observed examples of episodic cross shore exc . .nge (e.g. Grodsky et al., 2018b) within the NEC, upstream on the Scotian Shelf (Brickmc $n$ et 1l., 2018), and region-wide thermohaline changes (Holliday et al., 2020; Gawarkiewicz $\epsilon$ al., 2018) that may require consideration within the analyses.

This study will also attempt to extend findings made usin $n_{\zeta}$ 'nese five SMAP-observed winters using longer multi-decade model and buoy datase 3. C ne objective in the extended analysis is to revisit the topic of $\mathrm{N}$. Atlantic basin-scale $\mathrm{a}^{+} \ldots$.1. $\mathrm{sp}^{\text {' }}$.eric control of seasonal winds and linkages to indices such as the North Atlantic Oscillatio. (Hurrell et al., 2003). Multi-year NAO variations produce a tri-pole gyre-scale sea level pa`'ern with amplified subpolar gyre and stronger, coastward-shifted Gulfstream during pr slınged NAO+ events (Hakkinen and Rhines, 2004; Volkov et al., 2019; Chafik et al, 2919). The work of Li et al. (2014) suggested that, at least at the 450-day time scale, NAO in ra ts on the Scotian Shelf along-shore wind forcing has been weak or negligible in rece... te..des, while Grodsky et al. (2017) reported that shelf surface salinity is positively cos eland with NAO variations. How do winter-period forcing data and surface salinity observatiuns in the eastern Gulf of Maine relate to NAO forcing?

Several recent studies using satellite SSSA data in this region have illustrated that monthly surface salinity variations from the seasonal mean are often large enough ( $\sim 1 \mathrm{psu})$ to overcome known L-band satellite radiometer detection limits in cold water (SST $<6-8{ }^{\circ} \mathrm{C}$ ) conditions (Grodsky et al., 2018a; Grodsky et al., 2018b; Reul et al., 2020). The quality of coastal SMAP SSS data is also being improved to provide more accurate measurements within $50-100 \mathrm{~km}$ of the coast (Meissner et al., 2019). Thus there is a promise that now more than 10-year long satellite SSS data (Reul et al., 2020) may enhance the existing observing system. The following study uses a complement of satellite sea level, SST, SSS, and wind data to evaluate the possible 
interannual impact of regional wind variations on GoM freshwater anomalies from 2015-2020. This 5-year SMAP time series is then used in combination with longer in-situ observations and numerical simulations to evaluate the relative importance of wind-driven horizontal advection in controlling surface salinity within the Gulf of Maine and to shed further light on approaches for monitoring the two primary Gulf inflows.

\section{Data and Methods}

Satellite salinity: This study relies on satellite SSS from the SMAP mission. Global Level 3 SMAP SSS is available daily as an 8 -day running mean on a $0.25^{\circ}$ grid (version 4.0 produced by the Remote Sensing Systems, www.remss.com/missions/smap, Mels. ner et al., 2019). The surface footprint of each measurement is $39 \times 47 \mathrm{~km}$ so the effe tiv resolution is close to 40 $\mathrm{km}$. To decrease satellite SSS measurement noise, we use mo.thl $f$ averaged $70 \mathrm{~km}$-smoothed data. Although satellite SSS agrees with in-situ measur III $_{\mathrm{N}} \eta_{\mathrm{v}}$ in the warmer tropics to within $\sim 0.2$ psu (Lee, 2016; Reul et al., 2020), its accuracy at '11 ver latitudes and approaching coastlines is less certain due to several limitations $\mathrm{b}$ at 'ead to seasonally dependent SSS biases (Meissner et al., 2016). For the northwester I tla.tic, (Grodsky et al., 2018a) found a significant positive bias in absolute SMAP SSS coastwa $\cdot d$ of a $0.5 \%$ antenna land contamination flagging, which occupies a significant portion of th GoM (Grodsky et al., 2018b). As shown by e.g., (Boutin et al., 2016), the SSS anomaly, w'ıch is defined as the difference computed relative to a monthly satellite SSS climatology, affectively removes such seasonal biases along with the real seasonal cycle. For this study, the inonthly seasonal cycle at each grid point was estimated as the time mean for each calenr a 'muıth (based on the entire available SMAP period, April 2015 onward).

Other satellite data: This study relies on satellite SST from the Canadian Meteorological Centre. It is Level $4,0.1^{\circ}$ combined infrared, microwave, and in-situ daily analysis (https://podaac.jpl.nasa.gov/dataset/CMC0.1deg-CMC-L4-GLOB-v3.0) that is used for SMAP processing. The inclusion of microwave SST is important in this cloudy region, especially during the winter months. Monthly absolute dynamics topography and surface geostrophic currents are obtained from the AVISO multi-satellite merged altimeter dataset. These data are now distributed through the Copernicus Marine Environment Monitoring Service (http://marine.copernicus.eu). Even in coastal areas, these altimeter data show reasonable temporal variability verified against tide gauges (Cipollini et al., 2017). Gridded $10 \mathrm{~m}$ neutral 
winds merging measurements from all major satellite scatterometer missions (1993-2018) are described in (Bentamy et al., 2017) and available from the Ocean Heat Flux Project at https://wwz.ifremer.fr/oceanheatflux/Project. These data are extended up to the present using ASCAT scatterometer winds described in (Bentamy and Fillon, 2012).

Mooring data: The University of Maine Ocean Observing System (UMOOS) Gulf of Maine Moored Buoy Program operates several GoM coastal and deeper basin moorings (http://gyre.umeoce.maine.edu/buoyhome.php) and is a part of US northeast coastal monitoring of the NERACOOS Program. We focus on the mid-basin mooring (M01, 2003-present, Figure 1) located in Jordan Basin in the northeastern GoM. This buoy monitor temperature and salinity, including near-surface measurements at $z=1 \mathrm{~m}$. Daily buoy salı. itv anomalies were computed by subtracting the monthly seasonal cycle (based on the ful' $\mathrm{L}^{\prime}$ ov data temporal coverage) resampled daily using cubic spline interpolation. All bur, y Ja ha have been averaged daily, in part to reduce significant variability associated with tides.

Model simulations and atmospheric reanalysis: I Ic el data are used as supplementary data to confirm observation-based findings. To ex ımi e cuastal wind-induced ocean responses along Nova Scotia and adjacent coasts, this $\mathrm{s}^{+} \mathrm{udy}$ usc: a multi-decade integration of an $\sim 0.1^{\mathrm{o}}$ (tri-polar grid) eddy-resolving POP2 ocean circ is tion model driven by interannually varying atmospheric forcing from the Coordinated Ocer « ' $\mathrm{Cl}$ Keference Experiments and climatological river discharge. A more detailed desc 'iptı n of these model simulations was presented in e.g., (Johnson et al., 2016). Some asp sts of this model validation for the NW Atlantic shelf are present in (Grodsky et al. 20.7). In particular, it reproduces well the magnitude of salinity variability along the shelı - slope front and reasonably simulates shelf currents and their variability (see Fig. 9 and Fig. 11 therein), including the Nova Scotia and shelf-edge Currents. Mean sea level atmospheric pressure data are taken from the ERA5 atmospheric reanalysis (https://www.ecmwf.int/en/forecasts/datasets/reanalysis-datasets/era5).

Throughout this paper, anomalies are defined as deviations from the seasonal cycle.

\section{Results}

a. Seasonal cycle of surface fields 
Mixed layer salinity in the GoM has intermediate values between the freshest SSW and more salty WSW. The southwestward flow along the seaward side of Nova Scotia (the NSC) represents the freshest water in the region (Figure 2) and the main supply of fresh and cold water into the GoM. The impact of this freshwater advection on internal GoM salinity depends on several factors, including salinity contrast and inflow magnitude. In winter, while SSS in the central and western parts of the GoM increases due to mixing and entrainment, SSS in the eastern GoM and to the coast of Nova Scotia decreases due to low saline near-surface Sable Island inflow that peaks in January - February (Smith, 1983). The large wintertime zonal salinity gradient suggests that the fresher upstream SSW inflow may have : larger impact on internal GoM salinity in winter. In contrast to the winter circulation patte nn ( i igure 2a), NSC surface geostrophic current is greatly reduced in the summer with litt e on no evidence of low SSS intrusion into the GoM (Figure 2b).

The seasonal variations of local winds are in line with the easonal variations of the NSC. Summer deceleration of the NSC is, in part, relate $t^{t} \mathrm{~J}$ easonally prevailing southwesterly winds, which counteract the NSC by setting up the a 'su val seaward cross-shore pressure gradient through upwelling adjustment processes $(\mathrm{L1}+\mathrm{r}$., 2014). But local winter winds are mostly offshore (Figure 2a). This winter, the nor '⿳⺈冂䒑 westerly wind anomaly amplifies the local southwestward Ekman response and ler ds to winter NSC acceleration (see also discussions later on). Overall, the seasonal analysis $\eta$ Figure 2 suggests that freshwater intrusions into the GoM are seasonally dependent. The, an. plify in winter along with seasonal NSC acceleration, which is generally consistent wit ${ }^{2}$. nre :ous studies (Smith et al., 2001; Dever et al., 2016). Additionally, the NSC _. ay aiso carry salinity anomalies sourced by the Cabot Strait outflow from the Gulf of St. Lav._.nce and its upstream sources that pass through the Halifax section during September-October and arrive at southwest Nova Scotia later in the year (Brickman et al., 2016).

\section{b. Spatial statistics of SSS and SST anomalies}

Figure 3 shows satellite-derived SSS and SST anomalies (SSSA and SSTA) within the GoM and surrounding waters for the winter and summer seasons. Despite uncertainty due to the relatively short SMAP data record, Figure 3 indicates that winter salinity anomalies are larger than summer in the eastern $\mathrm{GoM}\left(\sim 43.5^{\circ} \mathrm{N}, 67^{\circ} \mathrm{W}\right)$, a result consistent with Mountain and Manning (1994). 
This is likely attributed to this same fall-to-winter maximum in NSC inflow off Cape Sable. Joint statistics of regional surface $\mathrm{T}$ and $\mathrm{S}$ anomalies may shed further light on their origins. As shown by e.g., Flagg et al. (2006), the correlation between upper ocean salinity and temperature anomalies is nominally positive when produced by horizontal advection, but negative when produced by vertical exchange due to the presence of the subsurface salinity maximum e.g., (Grodsky et al., 2017). Figures 3c and 3d show that during both winter and summer seasons the temporal correlation of salinity and temperature anomalies is positive over the Slope Sea. This positively correlated area extends from the Gulf Stream core (identified as maximum sea level variability area) to the shelf-slope front (identified in Figure 3 as th. maximum SSS variability area). One explanation for this correlation is advection from war $\mathrm{n}$ a d salty Gulfstream warm core meanders and rings e.g., (Csanady, 1979) that lie betwer $\mathrm{n}$ th : Gulfstream and the shelfslope front. These meanders normally don't penetrate onto . he shelf where local depths are shallower than their vertical scale. This leads to a weak $r n$ jgative anomaly correlation coastward of the shelf edge (Figures 3c, 3d). Mos $^{+} 11$ tably for this study, a moderately positively correlated area $(\geq 0.4)$ of anomalnus iSS and SST emerges in the winter in the NE GoM, consistent with expected horizontal a dv ective impacts due to varying NSC inflow. Results also imply that only in the winter and in the eastern half of the Gulf do SSSA variations become comparable with the much larger vari tb $1 . \mathrm{y}$ observed along the adjoining NW Atlantic shelfbreak front; a front roughly follow' ng the shelf break 1000m isobath (see Figures 3a and 3b).

c. Sea surface salinity anoma: os vver five Gulf of Maine winters observed with SMAP

In an attempt to understa $\mathrm{d} \mathrm{a}$. 'namical factors affecting near-surface salinity anomalies in the northeastern GoM, a seas nally-averaged SSS anomaly map is provided in Figure 4 for each winter during 2015-20 along with additional and potentially relevant near-surface observations. According to satellite SMAP records, SSS conditions in the GoM were close to neutral (weak anomalous SSS) in the winter of 2015-16 (Figure 4a). This was followed by a sequence of fresh and salty events in the following years (Figures $4 \mathrm{~d}, 4 \mathrm{~g}, 4 \mathrm{j}, 4 \mathrm{~m}$ ). Interestingly, not all GoM salinity variations have a corresponding imprint in the SST anomaly fields. While the 2017-18 and 2018-19 events (Figures 4g, 4j) have positively correlated SST signatures (Figures 4h, 4k), earlier years do not (compare Figures 4a, 4d and Figures 4b, 4e). The latest freshening observed in the winter of 2019-20 (Figures 4m, 4n) presents yet another example of GoM freshwater intrusion not accompanied by colder SST. This lack of correspondence is not unexpected given 
strong ocean heat loss in winters within the GoM. While upper ocean salinity is more conservative and most strongly affected by advection processes (Foltz et al., 2004), mixed layer temperature is also affected by the net surface heat flux (Foltz et al., 2003) and this may alter and mask advection-induced temperature anomalies.

Dynamical conditions in Figure 4 (right column) are shown one month before corresponding salinity patterns in Figure 4 (left column) consistent with the upstream advective timescales observed here in winter e.g., (Han et al., 1997; Feng et al., 2016). Although the accuracy of gridded altimetry sea level and its related geostrophic currents deteriorates approaching coasts e.g., (Feng et al., 2018), the altimeter sea level will be analyzed for tha presence of coastal patterns affecting the NSC. This altimeter application is based ot. the (Feng et al., 2016) analysis that shows that the variations of altimeter-derived geostrophi cur rent on Nova Scotia are reasonably linked with the variations of GoM salinity. $\mathrm{C} \sim$ truphic balance in the southwestward NSC suggests the presence of a sea level high along the $N \cdot$ va Scotian coast. Year-to-year variations of this coastal sea level high agree with ar or alous SSS in the northeastern GoM. During GoM freshening years (Figures $4 \mathrm{~d}, . \mathrm{J}, 7 \mathrm{~m}$, the apparent coastal sea level high was present (Figures 4f, 4l, 4o). By contrast, the - Ilty event of 2017-18 (Figure 4g) shows a virtual absence of this Nova Scotia coastal sea lt el high (Figure 4i) and the greatly attenuated NSC. In turn, this suggests that abnormally wed'. I I S freshwater transport in the winter of 2017-18 contributed to the salty anomaly i. Figure 4g. Anomalous wind patterns in Figure 4 (right) are highly variable and we will ret.rn $: 0$ their analysis after examining longer term joint variability of regional winds and sea $1 .$. e.

d. Salinity anomaly ana, ses at mooring M01, 2003-2020

The seasonal estimates of SSSA variability shown in Figure 3 are derived from relatively short SMAP satellite time series (since April 2015) that include only five winters. To sample over more winter observations, we turn to a potential proxy for eastern GoM SSSA by using data from mooring M01 in Jordan Basin (see Figure 1).

\section{i. Vertical structure of buoy salinity anomaly at the M01}

The monthly M01 buoy data from 2003-2020 provide vertically-resolved anomalous salinity (Figure 5a) with limited dropouts across the 17-year record. It is fairly well correlated throughout the water column at monthly time scales suggesting that SSS is a good indicator of salinity 
variability at deeper levels. Vertical EOF decomposition of anomalous salinity indicates that nearly $66 \%$ of the variance is accounted for by the first mode, thus salinity variations are mostly in phase through the full water column. The second mode indicates that $20 \%$ of the variance corresponds to out-of-phase oscillations between the upper $50 \mathrm{~m}$ and depths below $50 \mathrm{~m}$ (Figure $5 c$ ). This partitioning is inferred from monthly salinity anomalies and may not hold at shorter periods. In line with satellite SSS in Figure 3, in-situ salinity data also suggest that anomalous salinity magnitude peaks in winter months (Figure 5d) and decreases by at least a factor of two in summer months. This is also true for the anomalous salinity averaged over the upper $50 \mathrm{~m}$ and the leading EOF amplitude (PC1). The seasonal magnitude of the s_- ond EOF also peaks in winter but has a secondary extremum in summer probably reflec ing he seasonal mixed layer shallowing, which virtually separates mixed layer variability fron that at sub-thermocline depths.

\section{ii. Buoy-SMAP comparison}

During the SMAP period (2015-onward), daily z vc ao $\cdot d$ near-surface buoy M01 salinity anomaly measurements inside the GoM sh $\mathrm{sw}$, oou agreement with collocated SMAP SSSA (Figure 6a). The temporal correlation is $\sim 0.6$ a nd the standard deviation (STD) is $0.38 \mathrm{psu}$. During this period, available buoy sali $\ldots+{ }^{+} \mathrm{v}$ icords capture the three upper ocean winter

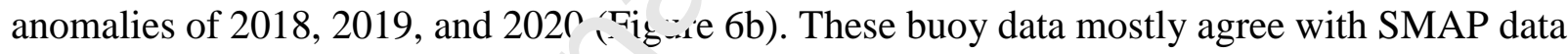
for a salty event in winter 2017 8 a. $\mathrm{d}$ fresh features in early 2019 and 2020 (Figure 4). The 2017-18 salty event was quite un : sual. Buoy M01 T/S analysis characterized it as a $\sim 100 \mathrm{~m}$ deep near-surface inflow :on osed of modified Atlantic WSW, typically observed only at depths below $100 \mathrm{~m}$ and ${ }_{\mathfrak{r}}$ reviously unobserved at the surface in this 15 -year buoy record (Grodsky et al., 2018b). It originated from interactions between a preexisting open ocean salty anomaly and a warm Gulf Stream meander that advected high salinity water onto the shelf and then into the northeastern GoM via the NEC-arriving at the station M01 as an about 1psu surface-trapped salty feature in late fall 2017 and lasting through early 2018. In the next two years (2019 and 2020), fresh winter anomalies ( 1 psu) are present in M01 observations (Figure 6). But in the first two years, buoy and satellite salinity data are closer to mean winter values. This suggests that the Jordan Basin buoy location may be less than ideal for monitoring surface water intrusions from Cape Sable because this advective pathway into the GoM is 
centered on the $100 \mathrm{~m}$ isobath off western Nova Scotia; a pathway 60-80 km east of the M01 deep basin mooring (Figure 3a).

The collocation of SMAP with M01 data in Figure 6a is done using the nearest SMAP grid point criterion. SMAP data include a random noise particularly evident in 1-grid point data. It leads to noticeable scatter in collocated SMAP time series. Another factor of SMAP-buoy deviation is in the difference between spatial sampling of satellite and mooring data. While the SMAP SSS is spatially smoothed over about $70 \mathrm{~km}$, the mooring M01 performs pointwise measurements. As mentioned above, the particular M01 location maybe not ideal for capturing GoM intrusions. Some salinity events get unobserved in pointwise buoy records but $g_{4}+$ captured in a 70-km wide satellite ground swath. An example of such spatial sampling disc.aps acy is the December 2016 fresh event that is partly captured by the SMAP but is almo st $\mathrm{bss}^{\prime} \mathrm{nt}$ in the buoy data (Figure 6a, see also Figure 4d and discussions of eastern GoM satel'iu S S SA index in Summary). There also exists a seasonally-dependent retrieval bias in SMAP drta, with positively biased SMAP SSS in the summer (compare buoy and SMAP seasonal c. 'c'es in Figure 6a). By design, SMAP SSSA estimates remove any seasonal retrieval bia ${ }_{-}$( $a_{1} \sim n g$ with the real seasonal cycle) in SMAP SSSA estimates. The resulting spatial SSS \& maps capture salinity anomalies associated with eastern GoM intrusions (Figure 4). In par, detection is possible because the relatively large SSSA magnitudes are comparable to ur er en exceed that of the seasonal SSS cycle (see Figure 6a for salinity at the buoy M01).

\section{e. Regional winds and sea lover 'nd their links with GoM salinity}

\section{i. Multivariate EOF $a\urcorner a l$, sis, faltimeter sea level and winds}

Focusing on wind-induc ar. variability in the GoM and surrounding areas, we perform a multivariate Empirical Orthogonal Function (EOF) analysis of anomalous monthly sea level and winds based on the entire altimeter record since 1993. The resulting time series is only shown from 2003 when M01 buoy observations become available (Figure 7). To avoid possible impacts of strong sea level anomalies associated with Gulf Stream meanders, the analysis domain excludes areas where the STD of sea level exceeds $6 \mathrm{~cm}$. The leading mode of variability is associated with alongshore winds (Figure 7a). Hereafter the alongshore component is defined as a projection on the general orientation of Nova Scotia seaward coastline, $26^{\circ}$ counterclockwise from the east, positive in northeastward direction. This is consistent with the valve mechanism of 
(Li et al., 2014) suggesting that upwelling-favorable southwesterly wind anomalies produce a sea level low along Nova Scotia and thus decelerate the NSC and its GoM inflow (Figure 7a). This EOF1 pattern also includes a northeastward gradient of sea level along the Nova Scotia seaward coast that balances the northeastward wind stress anomaly. The sea level low associated with this mode develops along the entire coastal region of the analysis domain and suggests below normal cyclonic circulation in the GoM during positive EOF1 phases.

The second mode of variability (Figure 7b) is associated with cross-shore winds. Surprisingly, the strengthening of onshore winds also decreases sea level along the seaward side of Nova Scotia and thus decelerates the NSC. Note that the sea level pressure ?radient associated with the coastal sea level low cannot balance the cross-shore wind stress ( >m jonent. Instead, the sum of the two is balanced by the Coriolis force associated with the i nor alous NSC. In distinction from the leading mode (Figure 7a), the sea level low develop $v^{-1}$ y along coastal Nova Scotia and doesn't extend into the northwestern GoM. This suggests ، ' at GoM salinity anomalies produced by Nova Scotia cross-shore winds may be observe 1 in he northeastern GoM, but may not extend further north and then west to impact the $\mathbf{M}$ in $~ \& \mathcal{C}^{\top}$ 'astal Current as seen with mode \#1.

\section{ii. Wind-driven NSC variability}

Comparing temporal amplitudes (PC) of the two leading EOFs with anomalous salinity at the M01 mooring (Figures 7c) deliver $m_{i}$ xed results. Note that the EOF sign is chosen in such a way that negative/positive EOF . mplitude in Figure 7a corresponds to northeasterly/southwesterly ina anomaly, accelerated/decelerated NSC, and fresher/saltier expected salinity in th ${ }^{\supset} n_{1}$ rth $\operatorname{costern}$ GoM, respectively. The above relationships imply a positive correlation between PC an 1 surface salinity in the northeastern GoM. In fact, during buoy M01 records (Figure 7c), strong negative PC1 episodes in the winters of 2005 and 2010 resulted in apparent fresh events in the GoM. But other PC1 wind events have weaker, if any, imprint on GoM salinity.

The geostrophic velocity anomaly averaged over the NSC index area shown in Figure 2a (NSCA $=u^{\prime} \cos \alpha+v^{\prime} \sin \alpha$ ) has only a marginal correlation with each principal component of the multivariate sea level and wind EOF (PC1 and PC2; CORR $\sim 0.3$, see Table 1). Here, $u^{\prime}$ and $v^{\prime}$ are the eastward and northward velocity anomaly components, respectively, and $\alpha=26^{\circ}$ is the average orientation of coastal Nova Scotia (counterclockwise from the east). Because the two 
EOF modes are additive, a net anomalous wind-driven term $\left(\mathrm{NSCA}_{\mathrm{w}}\right)$ can be defined as $\mathrm{NSCA}_{\mathrm{W}}=-\frac{g}{f} \cdot \frac{\partial H}{\partial x} \cos \alpha+\frac{g}{f} \cdot \frac{\partial H}{\partial y} \sin \alpha$, with $H=\mathrm{PC} 1 \cdot \mathrm{EOF} 1_{\mathrm{H}}+\mathrm{PC} 2 \cdot \mathrm{EOF} 2_{\mathrm{H}}$ as estimated from the first two sea level components of the multivariate EOF (Figures 7a, 7b). This term has a higher correlation with the altimeter-observed NSCA $(\sim 0.4$, Table 1$)$ than for either individual mode. Yet it is found that the correlation level of $\sim 0.67$ (Figure 8d) between buoy M01 salinity and the total geostrophic anomaly, NSCA, is almost double that for this net wind-driven component $\left(\mathrm{NSCA}_{\mathrm{W}}, \mathrm{CORR} \approx 0.35\right.$ in Table 1$)$. This implies that NSC freshwater transport variability is also forced by factors unrelated to the local winds. A s one example, the correlation between NSCA and NSCAw is weak across the extended 2012-2n16:me period in Figures 7 and 8. As discussed in Grodsky et al. (2017), this shelf-wide solt, ? - riod was related not only to NSC deceleration but also to shelf-edge current deceleratio 1.

\section{iii. Patterns of flow connectivity}

Because the NSC carries relatively fresh water, it is es nected that its inflow anomaly has the largest effect on near-surface salinity inside the : roM. At mooring M01, salinity anomalies lag the NSC transport anomaly by a month $\left.\left(\mathrm{F}_{\varepsilon}{ }^{\top}\right\lrcorner 9 \mathrm{a}\right)$ and impact mostly the upper $75 \mathrm{~m}$. Given NSC velocity variability $\left(\mathrm{STD}=0.015 \sim \mathrm{s}^{-1}\right)$, the regression magnitude in Figure 9a corresponds to $\sim 0.2$ psu salinity vari; tir, $:$ in response to one STD deviation of the current. Interestingly, there is also a weak ${ }^{*}$ bu statistically significant correlation between NSC transport anomalies and salinity a the NEC GoM mooring N01 (Figure 1 and Figure 9b). This suggests that a portion of NSC fr sshwater transport veers SW around Browns Bank and enters the GoM along the no 'he $n f^{\prime}$ 'ank of the NEC (Figure 2a).

The availability of modt ately long (2003 - present) salinity records at the moorings M01 and N01 permits further insight into the flow connectivity along the Nova Scotia - GoM region. Figure 9c depicts a spatial pattern of correlation between mooring M01 SSSA and the lagged (one month) upstream alongshore component of the geostrophic velocity anomaly. The correlation pattern is strongest along coastal Nova Scotia but also branches seaward along the 1000-m isobath suggesting some contribution from the shelf-edge current. NEC mooring N01 near-surface salinity shows only a marginal correlation with upstream currents (Figure 9d). This is partly explained by the complexity of NEC dynamics and the high variability of its thermohaline characteristics. Besides that, the mooring N01 correlation splits between the NSC 
and the shelf-edge current, with a similar indication that both upstream current branches do impact NEC surface layer salinity (see also Figure 9b).

Next, we revisit Figure 4 satellite SSS data during the SMAP period (since mid-2015) and their relationship with SST, winds, and sea level. During this period, the M01 mooring salinity corresponds qualitatively with altimeter-derived NSC transport (Figure 8c). In particular, the 2018 salty event and 2019, 2020 fresh events are all accompanied by corresponding NSC deceleration (positive alongshore velocity anomaly) and acceleration (negative) events (Figure 8c). But, due to M01 measurement gaps, the 2016-17 fresh event (Figure 4d) is not captured in M01 records (Figure 8c), see also Figure 14c in Grodsky et al. (20id. ). This illustrates that some of these coastal GoM water intrusions may go unobserved at this hur y M01 location (see also Figure 11 below).

\section{iv. Wind-GoM salinity links during the SMAP period}

Combining results of Figures 7a and 4 (left and rig'^s ?anels in 4), it can be seen that the larger winter SSS anomalies of the last four winters, $2^{\prime} 1 \%-2^{\prime} v 20$, qualitatively correspond with EOF1 of anomalous wind direction on the Scotian $s^{\prime}$ nel $^{\prime}$. Fresh conditions in Figures $4 \mathrm{~d}$ and $4 \mathrm{~m}$ correspond to weakened westerlies (do rnshelt wind anomalies) that accelerate the NSC (a stronger sea level high along seaward $\mathrm{N}$, , Scotia) and its SSW transport (Figures 4f and 4o). The opposite effect, associated wit a t. hanced westerlies, is observed in winter 2017-18 (Figures $4 \mathrm{~g}$ and $4 \mathrm{i}$ ). Not all events are so $\mathrm{i}$ ly associated with alongshore winds. In winter 2019 (Figures 4j and 41), the fresh northeaste. G iM and enhanced NSC are concurrent with offshore Scotian Shelf winds that acce!ra a a 1 ghtward Ekman transport (EOF2, Figure 7b). A more complex case is observed in the firs SMAP winter (2015-16, Figure 4a) when weak eastern GoM SSSA results from the superposition of positive EOF2 (southeasterly wind anomaly, Figures 4c, 7) and weakly negative EOF1 (easterly winds off northern seaward Nova Scotia). These opposing factors may have canceled each other. Although sizeable SSS anomalies are observed during four out of five SMAP winters (Figure 4), only two of them are accompanied by distinct SST anomalies (Figures 4h, k). This implies that SSS may be a better indicator of GoM water inflow anomalies during winter periods when SST gradients can be reduced by air-sea interactions. Also, as seen in Figures 4 a-m and alluded to earlier, the NW location of Jordan Basin station 
M01 may be sub-optimal for detecting eastern GoM salinity anomalies due to Cape Sable Inflow.

\section{v. Eastern Gulf of Maine (eGoM) salinity index}

The mapping capability of the SMAP satellite allows us to compute an area-wide anomaly index defined here as the monthly SSSA spatially-averaged over the eastern GoM (eGoM, see Figure 2a). Figure 10a shows that this eGOM index generally covaries with M01 SSSA but there are also significant periods of deviation. For example, it captures a fresh inflow event in late 2016 that is not observed at the M01 mooring. In winter (November-Fe' ruary), the temporal correlation between eGoM and M01 SSSA time series reaches C $S_{\wedge}$ R- $0.8_{0.54}^{0.91}$ (sub-indices hereafter show the $95 \%$ confidence range). The two time seri $s$ ' $10 u$ share similarly high correlations $(\sim 0.8)$ with NSCA. Although eGoM and M01 SS.: 1 are highly correlated, Figure 4 suggests that the SMAP eGoM may be an improved in ${ }^{\prime}$ cat $r$ of CSI events, again because station M01 is frequently located on the periphery of SiSA due to NSC inflow.

The winter eGoM time series has a statistically gnınicant correlation with Scotian Shelf winds spatially averaged over the NSC index are. $\left(F_{\text {\& gures }} 10 \mathrm{~b}\right.$ and $10 \mathrm{c}$, see Figure $2 \mathrm{a}$ for the area location). Based on five SMAP winters, its linear fit with previous month alongshelf $(U a)$ and cross-shelf $(U c)$ wind anomalies, eGc $M-0.37_{0.16}^{0.57} \cdot U a(t-1)+0.14_{-0.02}^{0.30} \cdot U c(t-1)+$ $0.02_{-0.14}^{0.19}$, is statistically significa $\mathrm{t}$ at he $95 \%$ confidence level, with $F$-value, $F=7.3>1$, and p-value, $p=0.5 \%<5 \%$ \% a eGoM index correlation with the previous month $U a$ is positive and reaches, $\mathrm{CORR}=\left\{\sigma_{0.21}^{\prime .82}\right.$ (Figure $10 \mathrm{~b}$ ), with the $95 \%$ confidence interval not intersecting zero. Afte, su tr cting the $U a$-correlated signal, $\triangle \mathrm{SSSA}=\mathrm{eGoM}-0.37 \cdot U a(t-$ 1), the residual $\triangle$ SSSA har a weaker and only marginally significant correlation with previous month cross-shelf winds, CORR $=0.4_{-0.06}^{0.72}$ (Figure 10c). The utility of this eGoM index will be further assessed as the SMAP dataset lengthens.

\section{f. Temporal-spatial assessment using POP2 ocean model data}

To further assess the conclusions drawn above from the use of shorter period datasets and satellite-based observations, the next focus is on the results derived from the eddy-resolving $0.1^{\circ}$ POP2 ocean model simulations detailed in section 2 (Figure 11). For consistency with the observation-based EOF analysis, the simulated monthly anomalous mixed layer current and salinity estimates along with atmospheric wind stress are decomposed using multivariate EOF 
analysis over a 19-year-long model run that is forced by interannually varying winds and climatological river discharge. This implies that river discharge does not directly impact interannual variability in these simulations. To avoid possible impacts of strong current variance associated with Gulf Stream meanders on the EOF analysis, the EOF analysis domain excludes areas where the STD of sea level exceeds $6 \mathrm{~cm}$. Results of Figure 11 show that, as for the observations, the southwesterly (alongshore) wind anomalies decelerate the NSC (Figure 11a), but accelerate fresh Gulf of St. Lawrence outflow along northeastern Cape Breton Island (refer to Figure 1 for geographic location names). In this model, the effect of NSC deceleration dominates and its resulting lower transport leads to higher salinity in a narrow oastal ribbon $(<50 \mathrm{~km})$ along and seaward of Nova Scotia. This saltier water eventually snte s the northeastern GoM through the Northern Channel and shallow areas adjacent to ('ape Sable (Cape Sable inflow). This water inflow is also supported by decelerated in-Gulf c.rrents along the southwestern side of Nova Scotia due to local onshore winds. This salty in. ${ }^{7} n v$ continues cyclonically in the Maine Coastal Current and eventually down to the Mid A ald .1ic Bight. As noted earlier, the buoy M01 location (Figure 11a) is located near the westiva. 7 eage of this northeastern GoM inflow salinity anomaly pattern.

Note also that Ekman transport associatec with southwesterly winds shifts the position of the Shelf Slope Front to the right of wind $\mathrm{d}$ rection, and thus induces a massive freshening in the southern part of the domain. Mo*e ver, the Cabot Strait outflow along northeastern Cape Breton Island is accelerated (in line with lie Ekman response to southwesterly winds) and thus accelerates freshwater trar ${ }_{\omega_{r}}{ }^{\prime} 1$. uut of the Gulf of St. Lawrence (see the vicinity of $46^{\circ} \mathrm{N}, 60^{\circ} \mathrm{W}$ in Figure 11a).

The second EOF mode of model simulations (Figure 11b) is associated with southeasterly (Nova Scotia onshore) winds. As in the observations (Figure 7), these simulations confirm that both along-shore and cross-shore winds impact along-shore currents on the Nova Scotia shelf. In comparison with the response to alongshore winds (Figure 11a), NSC deceleration occupies a wider coastal extent $(\sim 100 \mathrm{~km})$ that may be more accurately resolved by altimeter-based and SMAP observations. This may explain why the analysis of Feng et al. (2016) based on altimeterderived along-shore current (i.e. NSC) variability on the southwestern Scotian Shelf emphasizes the action of cross-shore winds. Southeasterly winds also decelerate the freshwater transport out of the Gulf of St. Lawrence along the northeastern coast of Cape Breton Island (Figure 11b) and 
this may additionally reduce NSC freshwater transport. Simulations show that this reduced freshwater transport along Nova Scotia reaches the northeastern GoM where it circulates cyclonically in the Gulf interior (Figure 11b), but has a weaker impact on GoM salinity in comparison with the alongshore wind-induced EOF1 (Figure 11a). In part, this weaker inflow is explained by downwelling-favorable winds along southwestern Nova Scotia, and thus locally accelerated in-Gulf current along this coast that counteracts the effect of decelerated NSC.

\section{Discussion and Summary}

\section{a. Local wind and basin-scale atmospheric variability}

Due to larger spatial scales in the atmosphere, the correlations br $\mathrm{cWt}$ ?n GoM thermohaline variations and regional wind anomalies may be a part of broz ler eleconnections with Atlanticwide atmospheric anomalies (e.g., Greene et al., 2013). At i'e basin scale, the atmosphere can elicit both near-immediate circulation response via win - dri en coastal dynamics (cf. Figures 8b, 8d and also Feng et al. (2016)), as well as at delaye : ime lags of months to years due to changes including shifts in Gulf Stream position and the ub $_{\mathrm{ru}}$ ar polar gyre (Taylor and Stephens, 1998; Mountain, 2012). We focus here on correl. tio's at zero lag. Using time series of mooring M01 salinity anomalies as the reference, the oncurrent Atlantic winds and mean sea level pressure (MSLP) anomalies are composited fo $\mathrm{s}$. nng fresh and salty GoM episodes selected when the magnitude of the first vertical buo Sa ${ }^{1}$ inty EOF exceeds half of its STD (PC1, Figure 5b). Figure 12a shows that strong wi ter GoM freshening coincides with a weakened Azores high and Icelandic low (Figure 12a). This iMSLP anomaly pattern resembles an NAO mode (climatedataguide.uc2* ec ' $1 / \mathrm{cl}$ mate-data/hurrell-north-atlantic-oscillation-nao-index-stationbased), but it is also shifte ! south and west. This shift leads to a larger wind anomaly on the Scotian Shelf, accelerating the NSC and amplifying fresh/cold CSI transport into the GoM. Notably, this MSLP anomaly pattern time series does not always covary with the NAO index. For example, the NAO was close to neutral in winter 2004-05 when the strongest fresh GoM anomaly in past decades occurred.

Greene and Pershing (2003) found that the NAO and NW Atlantic shelf SSTA are positively correlated. This regional SST variation belongs to a larger scale pattern in which fresh conditions in the GoM are accompanied by cold SSTs extending across the NW Atlantic shelf and further into the subtropical Atlantic (Figure 12c). Along with warming across the subpolar gyre and 
northern tropical Atlantic, the Atlantic-wide anomalous SST pattern resembles the classical tripole pattern of Xie and Tanimoto (1998). This is consistent with the negative wind anomaly seen in Figure 12a (weaker winds - warmer SST).

One important contrast that is highlighted when comparing Figure $12 \mathrm{~b}$ to12a is the lack of any apparent GoM-Scotian Shelf wind anomaly during periods of salty positive SSSA in the GoM. So while an $\mathrm{NAO}-$, an increased winter wind forcing appears central to interannual GoM freshening, the opposite may not be true for NAO+. Instead, it is more likely that salty events are the result of advection of warmer salty Gulf Stream or slope water disturbances into the Gulf or onto the Scotian Shelf (Brooks, 1987; Lee and Brink, 2010; Grods'rv et al., 2018b; Brickman et al., 2018). This mechanism is not directly wind-driven, nor it 1. a $r$ rocess known to preferentially occur in winter.

GoM salty and fresh episodes are related to a warmer ar d c lder NW Atlantic shelf, respectively (Figure 12). Positively correlated T and S shelf anoma'.es (‥g., Loder et al., 2001; Flagg et al., 2006; Grodsky et al., 2017) are density compens at 1. vhich allows for salty anomalies to stay afloat and be detectable from space. Upper ocf an a.lomaly trapping (Figure 4c) is corroborated by model analysis of GoM nitrogen flux (Zha. g et al., 2019) highlighting the importance of shallow to intermediate depth inflow $(07 \div \mathrm{m}$ ), at times exceeding the deep inflow (see also, Brickman et al., 2018). Similar to $\mathbf{1}^{\top} \mathrm{I}_{\mathrm{i}}$ and wind anomaly composites (Figures 12a,b), SST composites are not symmetrical or s.ilty and fresh GoM events. While the fresh episode SST composite involves pan-Atli $n$ tic IST anomalies (Figure 12c), the salty episode SSTA+ is limited to the shelf (Figu e $1<1$ ). This suggests that shelf-slope exchanges due to eddy dynamics may play a larger role in 1 rcing positive GOM SSSA periods.

\section{b. Summary}

New L-band satellite sea surface salinity (SSS) observations from the Soil Moisture Active Passive (SMAP) mission confirm the seasonal presence of significant winter period near-surface salinity variability in the northeastern Gulf of Maine (GoM). These wintertime satellite salinity observations are challenging because of weak L-band sensitivity to SSS change in cold water temperatures below $5^{\circ} \mathrm{C}$ that are common in the wintertime GoM. But accurate SMAP measurement of monthly ocean salinity anomalies is obtained (e.g., Figure 12) by applying a deseasoning procedure that calculates SSS anomalies by subtracting the observed seasonal cycle at 
each grid point. This procedure improves the accuracy of the residual anomalous SSS by removing the seasonally-dependent bias component along with the real seasonal cycle. Regional SMAP SSSA detection also benefits from the relatively large magnitude of winter SSS anomalies ( $0.5-1 \mathrm{psu})$. A multi-year analysis of these satellite SSSA data shows that larger anomalies are mostly confined to the northeastern GoM. Study results show that GoM salinity change is often associated with regional wind-driven ocean dynamics. Changes in Nova Scotia Current (NSC) inflow cause significant ( $\sim 1$ psu in amplitude) year-to-year variations in winter SSS in the northeastern GoM. Since 2015, three out of five winters of satellite SSS observations show the presence of such anomalies. These anomalies are confirm. 1 by in-situ data from the M01 mooring in the interior GoM. Their origin is, in part, attribu ted $\mathrm{o}$ wind-induced changes in freshwater transport of the NSC. But, the observed buoy neal-sur ace salinity anomalies correspond better to area-mean NSC variations averaged alo'g seaward Nova Scotia coast rather than to winds. This suggests that additional factors cont he to NSC variability. Alternative origins of salinity change at mooring I I 1 tre addressed in Table 1 where zero-lag correlations between this salinity anomaly a « se aral remote factors known to impact this shelf circulation. The highest correlation $(\sim 0.67)$; found with the NSC geostrophic velocity anomaly derived from altimeter data (NSCA). Con $>$ lations with the Gulf Stream North Wall index (GSNW) and North Atlantic Oscillatios ir dex (NAO) have marginal values close to 0.2 (the $95 \%$ confidence level). Noticeab $1 y$, the correlation with our estimate of the wind-driven component of NSC geostrophic veizcity anomaly (NSCAw) is lower than for the total

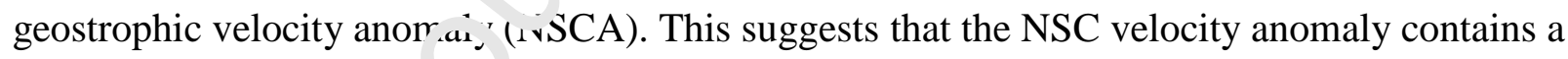
sizeable component not ${ }^{3} r_{1} \sim n$ by local instantaneous winds (cf. Han et al., 1997). Additional controls are briefly discussed in the Introduction with references to the Atlantic gyre response to large scale wind curl, which may affect the inner shelf circulation. These important relationships operate mostly on longer, multi-year periods through upstream impacts on the Nova Scotia shelf. The rich complexity of those impacts is beyond the scope of this study.

Results suggest that a wind-driven component impacts interannual NSC variability. Based on satellite altimetry and scatterometer winds, it is shown that NSC transport variability is influenced by variations from both alongshore and cross-shore wind components. Observation and model simulations show that northeasterly-to-northwesterly wind anomalies accelerate the NSC due to in-phase impacts of alongshore and cross-shore winds, and thus induce fresh 
anomalies downstream in the northeastern GoM while wind anomalies from the opposite azimuth quadrant decelerate the NSC. Wind anomalies from the other two azimuth quadrants have a mixed impact on the NSC due to opposing impacts of alongshore and cross-shore wind stress components. Our findings related to these wind velocity components on NSC transport are confirmed by analysis of $0.1^{\circ}$ global ocean model simulations. Simulation results also suggest that wind-induced modification of freshwater transport out of the Gulf of St. Lawrence may play an additional role in the GoM SSSA via a more remote upstream forcing (Han et al., 1997; Dever et al., 2016).

Despite wind anomalies that were similar to several previous years, w. inter 2018-19 sea level variations along coastal Nova Scotia (that define NSC to GoM tr. nsr ort) were significantly stronger. Although reasons for this recent NSC response amp ific ttion are not fully understood, the sign of year-to-year sea level change was consistent with corresponding wind changes. In winter 2017-18, the presence of a westerly-to-southwester. wind anomaly resulted in a virtual disappearance of the Nova Scotia coastal sea level b' $\mathrm{gl}$ and a significant reduction of the NSC. This relaxation partially contributed to the rus a salty anomaly in the eastern GoM along with the unusual surface-trapped inflow of $t_{\iota}$ - WSW through the NEC (Grodsky et al., 2018b). In contrast to salty conditions in the winc - of 2017-18, the next winter saw one of the strongest NSC accelerations during the SMAP $p$ f rir d since 2015. The fresh northeastern GoM anomaly associated with this latter NSC a $x$ leration event is captured by satellite SSS and is nicely depicted by in-situ data from $t_{1} \cdot n_{n}$ ooring M01 as a sudden, more than 1 psu, drop in upper $100 \mathrm{~m}$ salinity that develo 2018 and lasted through the middle of March 2019. SMAP also captu •es ine fresh northeastern GoM SSSA of winter 2019-20 that also occurred concurrently wiill stronger than normal NSC.

SMAP SSS mapping since 2015 allows us to compute a candidate satellite-based index for GoM salinity change. This is defined here using monthly SSSA data averaged over the eastern GoM (eGoM) area off southwestern Nova Scotia. This area is most directly affected by the Cape Sable inflow. The eGOM has a high correlation with, but also deviations from the M01 SSSA. For example, it captures a fresh inflow event in late 2016 that is not observed at the M01 mooring. The index also has a statistically significant correlation with Scotian Shelf wind anomalies. Its further utility will be assessed as the SMAP SSS data record lengthens. 
Study results assessing basin-scale impacts do agree, in part, with the others that find correlations between local hydrographic change along the US east coast and distant Atlantic locations that arise through NAO-like atmospheric patterns (e.g.., Piecuch et al., 2019; Volkov et al., 2019). This research shows that periodic GoM winter freshening events are also concurrently linked with similar wind patterns. But the same is not completely true for positive salinity anomalies in the Gulf where salty episodes don't exhibit a similarly strong correlation with large scale Atlantic winds. This lack of correlation suggests that local concurrent zero-lag wind does not always impact NSC relaxation and, in turn, salt increase observed at GoM mooring M01; at least since 2003. Moreover, the most common pathway of salty water in 1 sion into the GoM is through its deepest open ocean boundary, the NE channel (Smitl et ' $\dot{a}^{\prime}$. , 2012). This ingress, and its more complex circulation dynamics, is certain to impact $\perp 01$ iSSA. A related mechanism

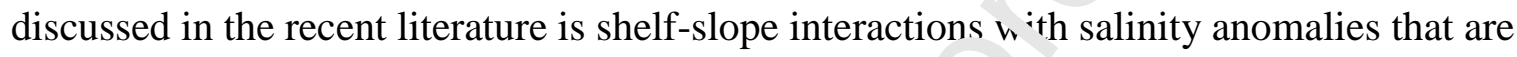
slowly propagating along the shelfbreak, and that eventu 11 s approach and entering the Gulf of Maine and St. Lawrence via the deeper channels (دi ckman et al., 2018; Grodsky et al., 2018b). We thus conclude that eastern GoM freshening - ay ve more dependent on and predictable by fall-to-winter wind anomalies on the Scotic ${ }^{n}$ ', nelf, whereas positive SSSA events also require monitoring of longer-term and larger-sc: le slope sea T and S behavior upstream and near the NEC.

Acknowledgments This research. supported by the NASA Ocean Salinity and Physical Oceanography Teams. N. Reul 1 supported by the French CNES/TOSCA Program. All data providers are acknowledged for , naking their products freely available. SMAP salinity data are produced by Remote Sens were provided by NEn A ${ }^{\prime} \mathrm{OC} S$ which is part of NOAA's Integrated Ocean Observing System (IOOS). AVISO altimete, products were processed by SSALTO/DUACS with support from CNES. Computing reso _...es for running the global eddy-resolving POP2 ocean circulation model were provided by the Computational and Information Systems Laboratory of NCAR. Anonymous reviewer inputs were very helpful and stimulating.

\section{References}

Bentamy, A., Fillon, D.C., 2012. Gridded surface wind fields from Metop/ASCAT measurements. Int. J. Remote Sens. 33, 1729-1754. doi:10.1080/01431161.2011.600348

Bentamy, A., Grodsky, S.A., Elyouncha, A., Chapron, B., Desbiolles, F., 2017. Homogenization of scatterometer wind retrievals. Int. J. Climatol. 37, 870-889. doi:10.1002/joc.4746

Bisagni, J.J., 2016. Salinity variability along the eastern continental shelf of Canada and the United States, 1973-2013. Cont. Shelf Res. 126, 89-109. doi:10.1016/j.csr.2016.08.003

Boutin, J., Martin, N., Kolodziejczyk, N., Reverdin, G., 2016. Interannual anomalies of SMOS sea surface salinity. Remote Sens. Environ. 180, 128-136. doi:10.1016/j.rse.2016.02.053 
Brickman, D., Hebert, D., Wang, Z., 2018. Mechanism for the recent ocean warming events on the Scotian Shelf of eastern Canada. Cont. Shelf Res. 156, 11-22. doi:10.1016/j.csr.2018.01.001

Brickman, D., Wang, Z., DeTracey, B., 2016. Variability of Current Streams in Atlantic Canadian Waters: A Model Study. Atmosphere-Ocean 54, 218-229. doi:10.1080/07055900.2015.1094026

Brooks, D.A., 1987. The influence of warm-core rings on slope water entering the Gulf of Maine. J. Geophys. Res. 92, 8183. doi:10.1029/JC092iC08p08183

Chafik, L., Nilsen, J.E.Ø., Dangendorf, S., Reverdin, G., Frederikse, T., 2019. North Atlantic Ocean Circulation and Decadal Sea Level Change During the Altimetry Era. Sci. Rep. 9, 1041. doi:10.1038/s41598-018-37603-6

Cipollini, P., Calafat, F.M., Jevrejeva, S., Melet, A., Prandi, P., 2017. Monitoring Sea Level in the Coastal Zone with Satellite Altimetry and Tide Gauges. Sı v. Geophys. 38, 33-57. doi:10.1007/s10712-016-9392-0

Csanady, G.T., 1979. The birth and death of a warm core ring. J. Ter phys. Res. doi:10.1029/jc084ic02p00777

Dever, M., Hebert, D., Greenan, B.J.W., Sheng, J., Smith, ' '.C., ¿016. Hydrography and Coastal Circulation along the Halifax Line and the Connectivis vith the Gulf of St. Lawrence. Atmosphere-Ocean 54, 199-217. doi:10.1080/070_,590 J.2016.1189397

Feng, H., Vandemark, D., Levin, J., Wilkin, J., 2018 Examining the Accuracy of GlobCurrent Upper Ocean Velocity Data Products on the I J iti western Atlantic Shelf. Remote Sens. 10, 1205. doi:10.3390/rs10081205

Feng, H., Vandemark, D., Wilkin, J., 2016 Go f ol Maine salinity variation and its correlation with upstream Scotian Shelf currents at easonal and interannual time scales. J. Geophys. Res. Ocean. 121, 8585-8607. doi: : ?.1002/2016JC012337

Flagg, C.N., Dunn, M., Wang, D.P., R usb, H.T., Benway, R.L., 2006. A study of the currents of the outer shelf and upper slope ro $n$ a decade of shipboard ADCP observations in the Middle Atlantic Bight. J. Ger.ohy. Res. Ocean. doi:10.1029/2005JC003116

Foltz, G.R., Grodsky, S.A., Cart sn, s A., McPhaden, M.J., 2004. Seasonal salt budget of the northwestern tropical Atla. 'tic Ocean along $38^{\circ} \mathrm{W}$. J. Geophys. Res. Ocean. 109, C03052. doi:10.1029/2003JC00<:11

Foltz, G.R., Grodsky, S.f ., C rton, J.A., McPhaden, M.J., 2003. Seasonal mixed layer heat budget of the tropı \ 1 islantic Ocean. J. Geophys. Res. 108, 3146. doi:10.1029/2002JC( ) 1584

Gawarkiewicz, G., Todd, R., Zhang, W., Partida, J., Gangopadhyay, A., Monim, M.-U.-H., Fratantoni, P., Malek Mercer, A., Dent, M., 2018. The Changing Nature of Shelf-Break Exchange Revealed by the OOI Pioneer Array. Oceanography 31, 60-70. doi:10.5670/oceanog.2018.110

Greene, C.H., Pershing, A.J., 2000. The response of Calanus finmarchicus populations to climate variability in the Northwest Atlantic: basin-scale forcing associated with the North Atlantic Oscillation. ICES J. Mar. Sci. 57, 1536-1544. doi:10.1006/jmsc.2000.0966

Greene, C.H., Pershing, A.J., 2003. The flip-side of the North Atlantic Oscillation and modal shifts in slope-water circulation patterns. Limnol. Oceanogr. 48, 319-322. doi:10.4319/lo.2003.48.1.0319

Greene, C.H., Meyer-Gutbrod, E., Monger, B.C., McGarry, L.P., Pershing, A.J., Belkin, I.M., Fratantoni, P.S., Mountain, D.G., Pickart, R.S., Proshutinsky, A., Ji, R., Bisagni, J.J., Hakkinen, S.M.A., Haidvogel, D.B., Wang, J., Head, E., Smith, P., Reid, P.C., Conversi, A., 
2013. Remote climate forcing of decadal-scale regime shifts in Northwest Atlantic shelf ecosystems. Limnol. Oceanogr. 58, 803-816. doi:10.4319/lo.2013.58.3.0803

Grodsky, S.A., Reul, N., Chapron, B., Carton, J.A., Bryan, F.O., 2017. Interannual surface salinity on Northwest Atlantic shelf. J. Geophys. Res. Ocean. 122, 3638-3659. doi:10.1002/2016JC012580

Grodsky, S.A., Vandemark, D., Feng, H., 2018a. Assessing Coastal SMAP Surface Salinity Accuracy and Its Application to Monitoring Gulf of Maine Circulation Dynamics. Remote Sens. 2018, Vol. 10, Page 1232 10, 1232. doi:10.3390/RS10081232

Grodsky, S.A., Vandemark, D., Feng, H., Levin, J., 2018b. Satellite detection of an unusual intrusion of salty slope water into a marginal sea: Using SMAP to monitor Gulf of Maine inflows. Remote Sens. Environ. 217, 550-561. doi:10.1016/j.rse.2018.09.004

Hakkinen, S., Rhines, P., 2004. Decline of Subpolar North Atlantic Circulation During the 1990s. Science (80-. ). 304, 555-559. doi:10.1126/science.10 1917

Han, G., Hannah, C.G., Loder, J.W., Smith, P.C., 1997. Seasona ${ }^{1}$ variation of the threedimensional mean circulation over the Scotian Shelf. J. Geo, 'hv, Res. Ocean. 102, 10111025. doi:10.1029/96JC03285

Hare, J.A., Morrison, W.E., Nelson, M.W., Stachura, M.M. T七uers, E.J., Griffis, R.B., Alexander, M.A., Scott, J.D., Alade, L., Bell, R.J., Cn 'te, A.S., Curti, K.L., Curtis, T.H., Kircheis, D., Kocik, J.F., Lucey, S.M., McCandless, C Г., Milke, L.M., Richardson, D.E., Robillard, E., Walsh, H.J., McManus, M.C., Marcncik, K.E., Griswold, C.A., 2016. A Vulnerability Assessment of Fish and Inverte oratı s to Climate Change on the Northeast US Continental Shelf. PLoS One 11. doi:10 12''1/juurnal.pone.0146756

Holliday, N.P., Bersch, M., Berx, B., Chaf к, J ., Cunningham, S., Florindo-López, C., Hátún, H., Johns, W., Josey, S.A., Larsen, K.M.H., Mulet, S., Oltmanns, M., Reverdin, G., Rossby, T., Thierry, V., Valdimarsson, H., Yas hayaev, I., 2020. Ocean circulation causes the largest freshening event for 120 years in _..ste.n subpolar North Atlantic. Nat. Commun. doi:10.1038/s41467-020-14474-y

Hurrell, J.W., Kushnir, Y., Otterse 1, C Visbeck, M., 2003. An overview of the North Atlantic Oscillation, in: Geophysicr Mc nograph Series. pp. 1-35. doi:10.1029/134GM01

Johnson, B.K., Bryan, F.O., G \ds:y, S.A., Carton, J.A., 2016. Climatological Annual Cycle of the Salinity Budgets of ives ubtropical Maxima. J. Phys. Oceanogr. 46, 2981-2994. doi:10.1175/jpo-d-1,-0<22.1

Lee, C.M., Brink, K.H., ? incursion over the so' thern flank of Georges Bank: Winter and summer 1997. J. Geophys. Res. 115, C08008. doi:10.1029/2009JC005706

Lee, T., 2016. Consistency of Aquarius sea surface salinity with Argo products on various spatial and temporal scales. Geophys. Res. Lett. 43, 3857-3864. doi:10.1002/2016GL068822

Li, Y., Ji, R., Fratantoni, P.S., Chen, C., Hare, J.A., Davis, C.S., Beardsley, R.C., 2014. Windinduced interannual variability of sea level slope, along-shelf flow, and surface salinity on the Northwest Atlantic shelf. J. Geophys. Res. Ocean. 119, 2462-2479. doi:10.1002/2013JC009385

Loder, J.W., Petrie, B.D., Gawarkiewicz, G., 1997. The Coastal Ocean off Northeastern North America: A Large-Scale View, in: Robinson, A.R., Brink, K.H. (Eds.), The Sea, Volume 11. Harvard University Press, pp. 105-133.

Loder, J.W., Shore, J.A., Hannah, C.G., Petrie, B.D., 2001. Decadal-scale hydrographic and circulation variability in the Scotia-Maine region. Deep Sea Res. Part II Top. Stud. Oceanogr. 48, 3-35. doi:10.1016/S0967-0645(00)00080-1 
McGillicuddy, D.J.J., Townsend, D.W., He, R., Keafer, B.A., Kleindinst, J.L., Li, Y., Manning, J.P., Mountain, D.G., Thomas, M.A., Anderson, D.M., 2011. Suppression of the 2010 Alexandrium fundyense bloom by changes in physical, biological, and chemical properties of the Gulf of Maine. Limnol. Oceanogr. 56, 2411-2426. doi:10.4319/lo.2011.56.6.2411

Meissner, T., Wentz, F. J., Manaster, A., Lindsley, R., 2019. Remote Sensing Systems SMAP Ocean Surface Salinities [Level 2C, Level 3 Running 8-day, Level 3 Monthly], Version 4.0 validated release. [WWW Document]. doi:0.5067/SMP40-3SMCS

Meissner, T., Wentz, F.J., Scott, J., Vazquez-Cuervo, J., 2016. Sensitivity of Ocean Surface Salinity Measurements From Spaceborne L-Band Radiometers to Ancillary Sea Surface Temperature. IEEE Trans. Geosci. Remote Sens. 54, 7105-7111. doi:10.1109/TGRS.2016.2596100

Mountain, D., Kane, J., 2010. Major changes in the Georges Bank ecosystem, 1980s to the 1990s. Mar. Ecol. Prog. Ser. 398, 81-91.

Mountain, D.G., 2012. Labrador slope water entering the Gulf of ivin Atlantic Oscillation. Cont. Shelf Res. 47, 150-155. doi:10.1 116 j.csr.2012.07.008

Mountain, D.G., Manning, J.P., 1994. Seasonal and interann al v riability in the properties of the surface waters of the Gulf of Maine. Cont. Shelf P $>$ s. uul:10.1016/0278-4343(94)900906

Pershing, A.J., Alexander, M.A., Hernandez, C.M., Kerı, I A., Le Bris, A., Mills, K.E., Nye, J.A., Record, N.R., Scannell, H.A., Scott, J.D. St.erwosd, G.D., Thomas, A.C., 2015. Slow adaptation in the face of rapid warming leads tr $\mathrm{c}$ )llapse of the Gulf of Maine cod fishery. Science (80-. ). 350, 809-812. doi:10.1126: science.aac9819

Piecuch, C.G., Dangendorf, S., Gawarkiev ıcz G.G., Little, C.M., Ponte, R.M., Yang, J., 2019. How is New England Coastal Sea Leve: Related to the Atlantic Meridional Overturning Circulation at $26^{\circ}$ N? Geophys. Rt. Lett. 46, 5351-5360. doi:10.1029/2019GL083073

Ramp, S.R., Schlitz, R.J., Wright, W.P... 1s?5. The Deep Flow through the Northeast Channel, Gulf of Maine. J. Phys. Oceanogr. dr 1:10.1175/15200485(1985)015<1790:TDFT N ? .0.CO;2

Reul, N., Grodsky, S.A., Arias, ' 1., 'outin, J., Catany, R., Chapron, B., D’Amico, F., Dinnat, E., Donlon, C., Fore, A., Fou niє., S., Guimbard, S., Hasson, A., Kolodziejczyk, N., Lagerloef, G., Lee, T., Le Vine, D.^^., indstrom, E., Maes, C., Mecklenburg, S., Meissner, T., Olmedo, E., Sabia, I.., 'I nerelli, J., Thouvenin-Masson, C., Turiel, A., Vergely, J.L., Vinogradova, N., I'en. L-band radiometers: in overview of the first decade of observation (2010-2019). Remote Sens. Environ. 242, 111769. doi:10.1016/J.RSE.2020.111769

Richaud, B., Kwon, Y.-O., Joyce, T.M., Fratantoni, P.S., Lentz, S.J., 2016. Surface and bottom temperature and salinity climatology along the continental shelf off the Canadian and U.S. East Coasts. Cont. Shelf Res. 124, 165-181. doi:10.1016/j.csr.2016.06.005

Runge, J.A., Ji, R., Thompson, C.R.S., Record, N.R., Chen, C., Vandemark, D.C., Salisbury, J.E., Maps, F., 2014. Persistence of Calanus finmarchicus in the western Gulf of Maine during recent extreme warming. J. Plankton Res. doi:10.1093/plankt/fbu098

Smith, P.C., 1983. The Mean and Seasonal Circulation off Southwest Nova Scotia. J. Phys. Oceanogr. 13, 1034-1054. doi:10.1175/1520-0485(1983)013<1034:TMASCO >2.0.CO;2

Smith, P.C., Houghton, R.W., Fairbanks, R.G., Mountain, D.G., 2001. Interannual variability of boundary fluxes and water mass properties in the Gulf of Maine and on Georges Bank: 1993-1997. Deep Sea Res. Part II Top. Stud. Oceanogr. 48, 37-70. doi:10.1016/S09670645(00)00081-3 
Smith, P.C., Pettigrew, N.R., Yeats, P., Townsend, D.W., Han, G.Q., 2012. Regime Shift in the Gulf of Maine, in: Stephenson, RL; Annala, JH; Runge, JA; Hall-Arber, M. (Ed.), ADVANCING AN ECOSYSTEM APPROACH IN THE GULF OF MAINE, 79. AMER FISHERIES SOC, BETHESDA, MD, USA, St Andrews, CANADA, pp. 185-203.

Taylor, A.H., Stephens, J.A., 1998. The North Atlantic Oscillation and the latitude of the Gulf Stream. Tellus A Dyn. Meteorol. Oceanogr. 50, 134-142. doi:10.3402/tellusa.v50i1.14517 TOWNSEND, D.W., 1991. INFLUENCES OF OCEANOGRAPHIC PROCESSES ON THE BIOLOGICAL PRODUCTIVITY OF THE GULF OF MAINE. Rev. Aquat. Sci. 5, $211-$ 230.

Townsend, D.W., Pettigrew, N.R., Thomas, M.A., Neary, M.G., McGillicuddy Jr., D.J., O'Donnell, J., 2015. Water masses and nutrient sources to the Gulf of Maine. J. Mar. Res. 73, 93-122. doi:10.1357/002224015815848811

Volkov, D.L., Lee, S., Domingues, R., Zhang, H., Goes, M., 2019. 'nterannual Sea Level Variability Along the Southeastern Seaboard of the United 'ca's in Relation to the GyreScale Heat Divergence in the North Atlantic. Geophys. Res. I.et.. 46, 7481-7490. doi:10.1029/2019GL083596

Xie, S.-P., Tanimoto, Y., 1998. A pan-Atlantic decadal clin ate uscillation. Geophys. Res. Lett. 25, 2185-2188. doi:10.1029/98GL01525

Zhang, S., Stock, C.A., Curchitser, E.N., Dussin, R., 20, . . Numerical Model Analysis of the Mean and Seasonal Nitrogen Budget on the North.east J.S. Shelf. J. Geophys. Res. Ocean. 2018JC014308. doi:10.1029/2018JC014308

Zorz, J., Willis, C., Comeau, A.M., Langille. M. T.I., Johnson, C.L., Li, W.K.W., LaRoche, J., 2019. Drivers of Regional Bacterial C om aunicy Structure and Diversity in the Northwest Atlantic Ocean. Front. Microbiol. 10. a ‘:10.3389/fmicb.2019.00281

Table 1. (top) Temporal correlation of ' - Um monthly salinity anomaly (SALTA) at mooring M01 with altimeter-derived Nova ico $a$ Current geostrophic velocity anomaly (NSCA), Gulf Stream North Wall index (GSN ${ }^{\vee}$ ), 1 'orth Atlantic Oscillation index (NAO), and wind-driven component of NSC geostrophic 'elocity anomaly (NSCAw). (bottom) NSCA correlation with amplitudes (PC1, PC2) of ${ }^{+} \mathrm{O}$ ading wind EOFs and NSCAw. M01 correlations exceeding their $95 \%$ significanc le el for magnitudes $>0.2$ are shown in bold. NSC-wind correlations are based on longer time serı s since 1993 and are statistically significant for magnitudes $>0.15$.

\begin{tabular}{|c|c|c|c|c|c|c|}
\hline & NSCA & GSNW & NAO & PC1 & PC2 & NSCAw \\
\hline SALTA@M01 & $\mathbf{0 . 6 6}$ & $\mathbf{0 . 2 4}$ & 0.19 & & & 0.35 \\
& $1 \mathrm{mo}$ & $3 \mathrm{mo}$ & $1 \mathrm{mo}$ & & & $1 \mathrm{mo}$ \\
\hline NSCA & & & & 0.3 & 0.25 & 0.39 \\
& & & & $0 \mathrm{mo}$ & $0 \mathrm{mo}$ & $0 \mathrm{mo}$ \\
\hline
\end{tabular}




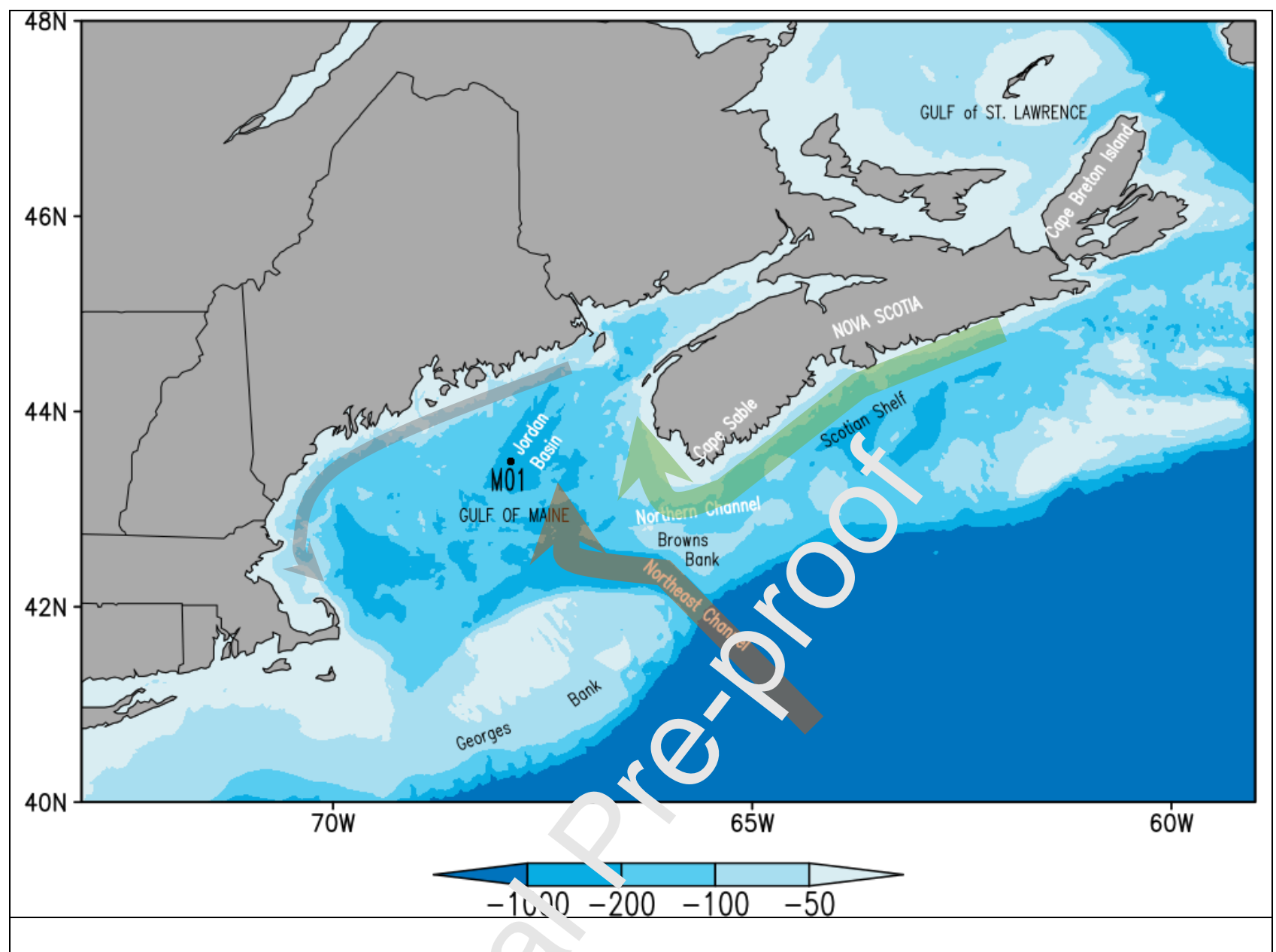

Figure 1. Gulf of Maine and adjacent $\bar{r} \cdot \bar{g}$ on bathymetry (meter, blue shades). Scheme of two major inflow pathways: (greenish; fresı/cold inflow by the Nova Scotia Current, (reddish) warm/salty Northeastern Channc' intıow. Cyclonic Maine Coastal Current is sketched in gray. NERACOOS mooring location 1 Jordan Basin is shown. 


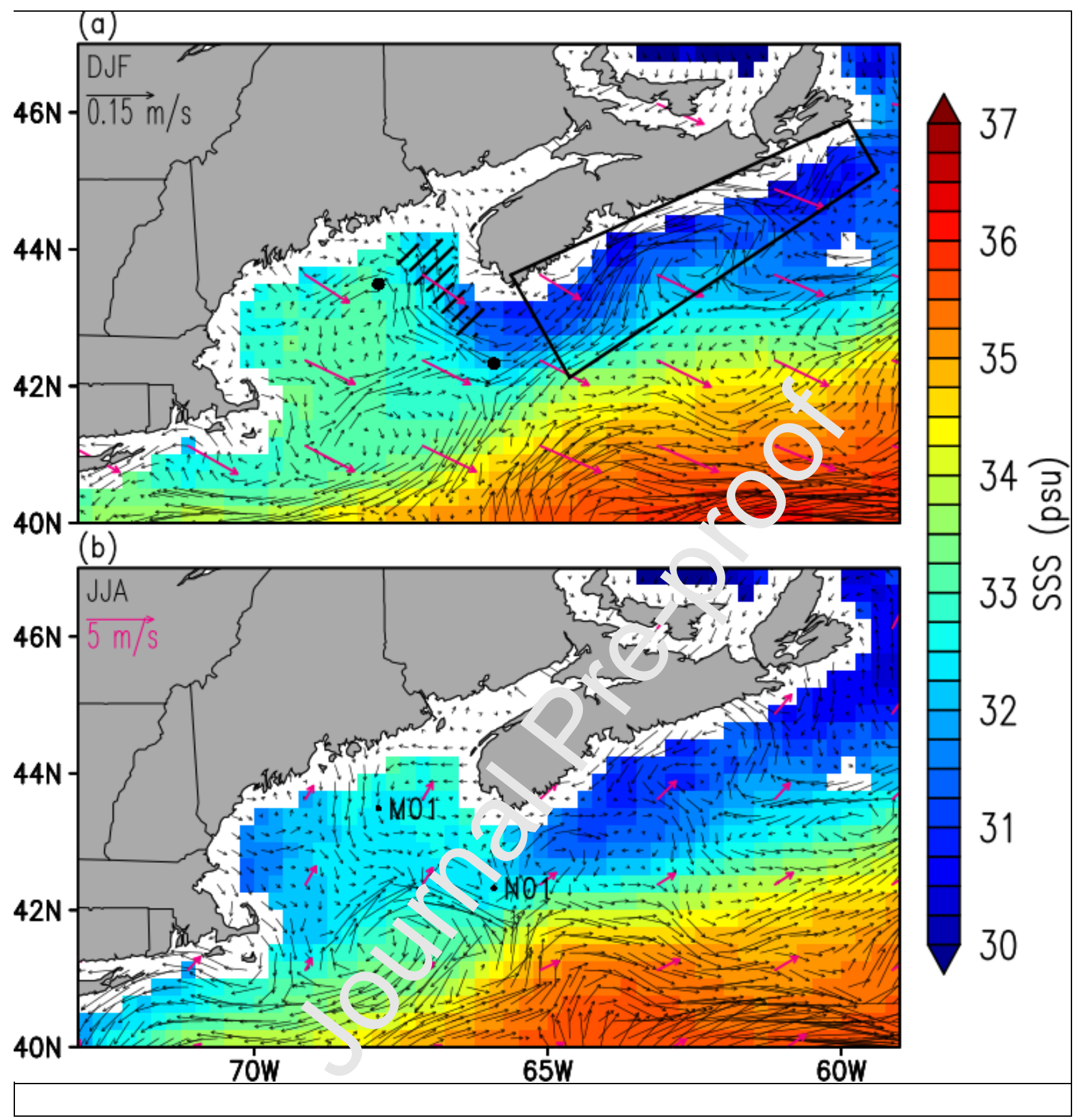

Figure 2. Winter (DJF) and summer (JJA) climatologies for the Gulf of Maine and adjacent region. Shown are SMAP V4.0 sea surface salinity (SSS), altimeter geostrophic currents (black arrows, AVISO), and scatterometer winds (magenta arrows). In panel (a), Nova Scotia Current and eastern Gulf of Maine index areas are shown by the black box and lines, respectively. NERACOOS buoy M01 and N01 locations are shown in both panels. 


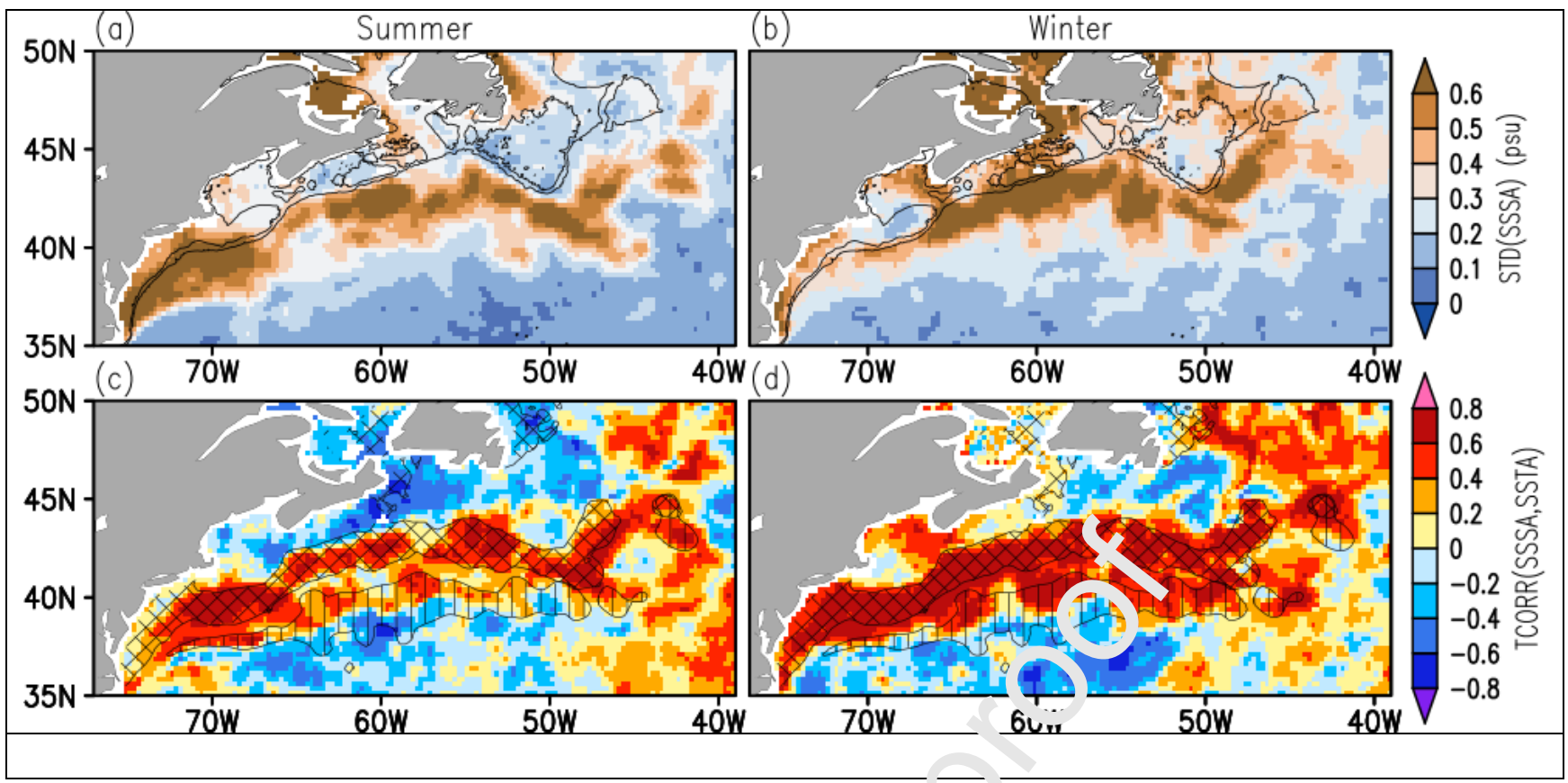

Figure 3. Standard deviation (STD) of anomalous $\mathrm{SM}_{\mathrm{s}} \overline{\mathrm{D}} \mathrm{m}$ गnthly sea surface salinity (SSSA) for (a) summer (JJA) and (b) winter (DJF) seasons. (c,, ) Tt.nporal correlation of SSSA with anomalous sea surface temperature (SSTA). Black $c$ sn ours in $(a, b)$ are $100 \mathrm{~m}$ and $1000 \mathrm{~m}$ isobaths. Gulf Stream core (vertical hatching) is llustrated as maximum sea level variability area, STD(SSHA) $>0.25 \mathrm{~m}$, shelf-slope fro ' (c oss-natching) is identified as maximum SSS variability area, $\operatorname{STD}(\mathrm{SSSA})>0.5$ psu.. 

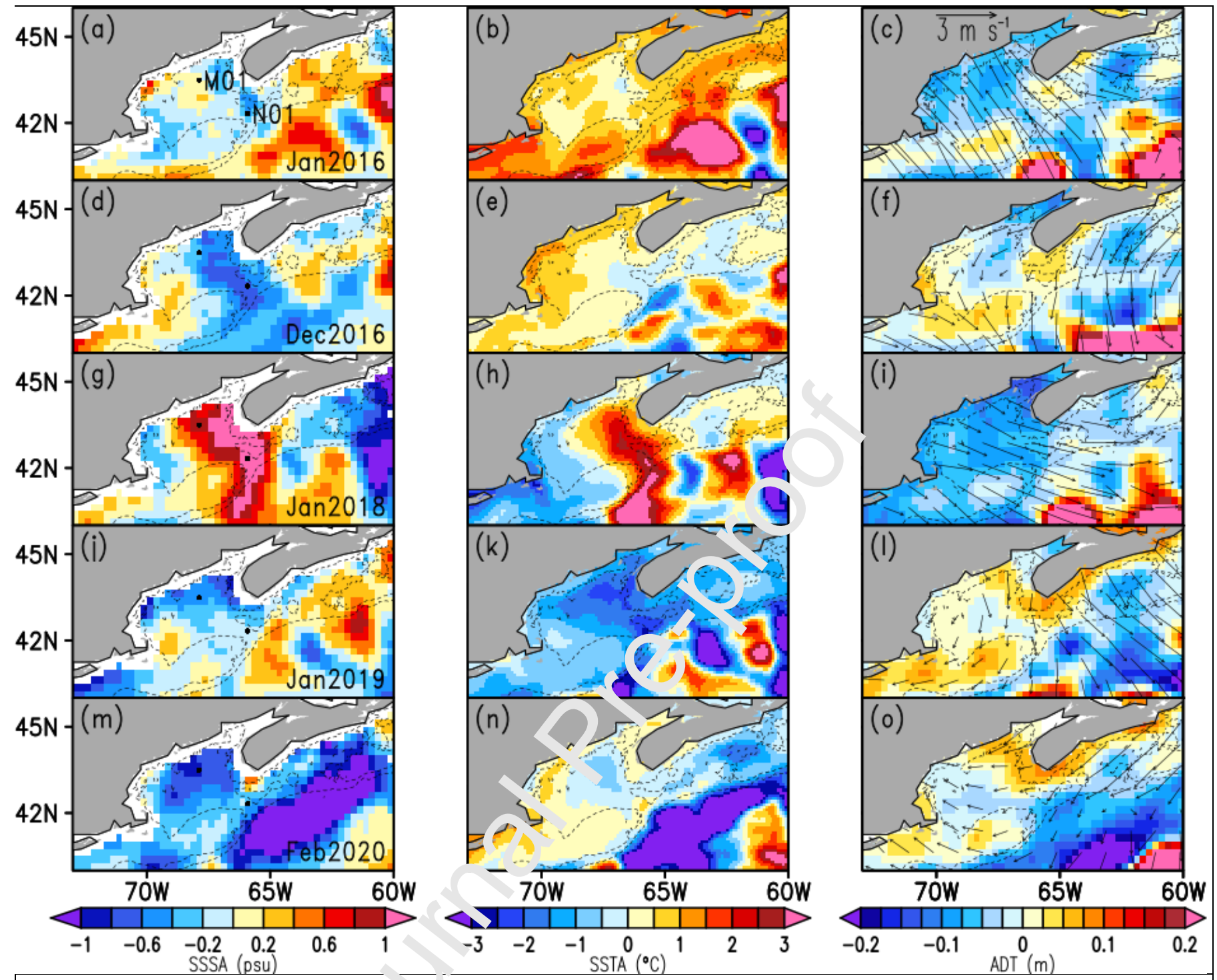

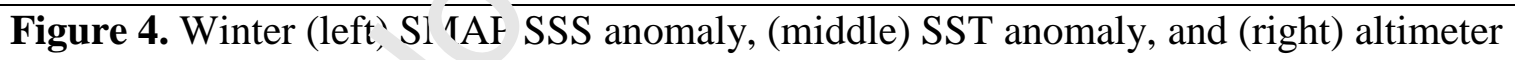
absolute dynamics topog. phy (ADT) and scatterometer wind anomaly. For each winter, the month is selected based uil the maximum SSSA (e.g., December 2016 for winter of 2016-17). Variables in the two left columns are shown for the current month (event peak), while the right column shows data for the previous month. Depth contours $(100 \mathrm{~m}$ and $1000 \mathrm{~m})$ are overlain. NERACOOS mooring M01 and N01 locations are shown in the left column. 


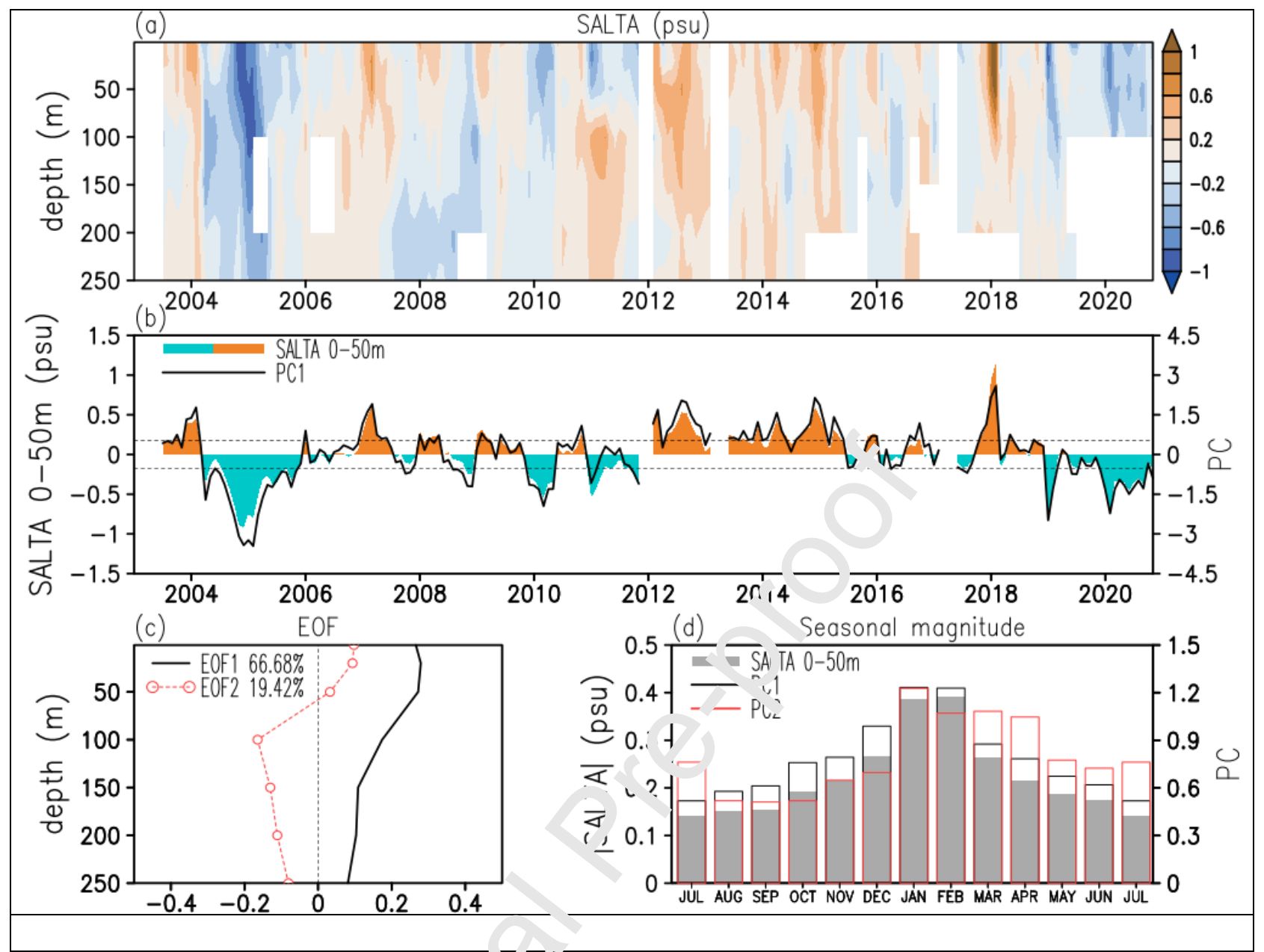

Figure 5. (a) Time-depth diagram $r^{f} \mathrm{~m} \sim \bar{r}$ hly anomalous salinity (SALTA) from M01 mooring in the Gulf of Maine. (b) Time sel. 's or 0-50m averaged anomalous salinity and the first EOF amplitude (PC1) with half standa-d deviation of PC1 shown by horizontal dash lines. (c) Two leading vertical modes of buny $\triangle 1$ LTA (numbers indicate the percentage of explained variance). (d) Seasonal magnitude (r us luce values averaged for each calendar month) of $0-50 \mathrm{~m}$ salinity anomaly and amplitua $c^{c}$ tr 2 two leading EOFs. 


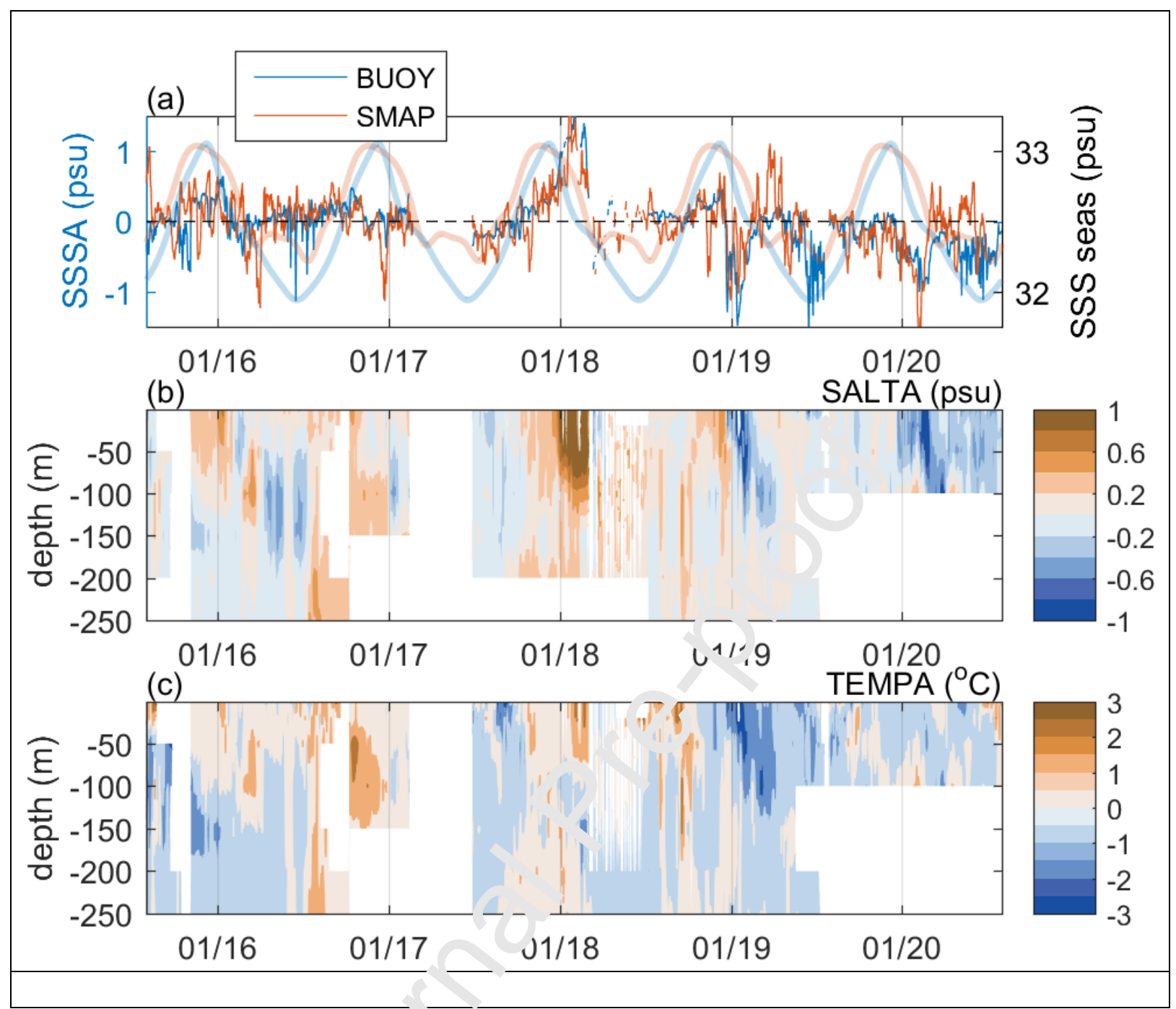

Figure 6. (a) Anomalo 's cily sea surface salinity (SSSA) from NERACOOS buoy M01 and collocated SMAi (ag ainst lhs y-axis) and SSS seasonal cycle (SSS seas, against rhs y-axis), anomalou, ( $\mathrm{c}$, salinity (SALTA), and (c) de-trended temperature (TEMPA) versus depth fru $\eta_{\llcorner}{ }^{\prime}{ }^{\prime}, \mathrm{y}$ M01 during SMAP observation period. In situ anomalies are calculated versus $\perp 101$ record-long (2003-19) climatological cycles, SMAP SSSA is calculated versus the mission-long SSS climatology. Missing surface buoy data are filled with $20-\mathrm{m}$ data if mixed layer depth $>20 \mathrm{~m}$. 


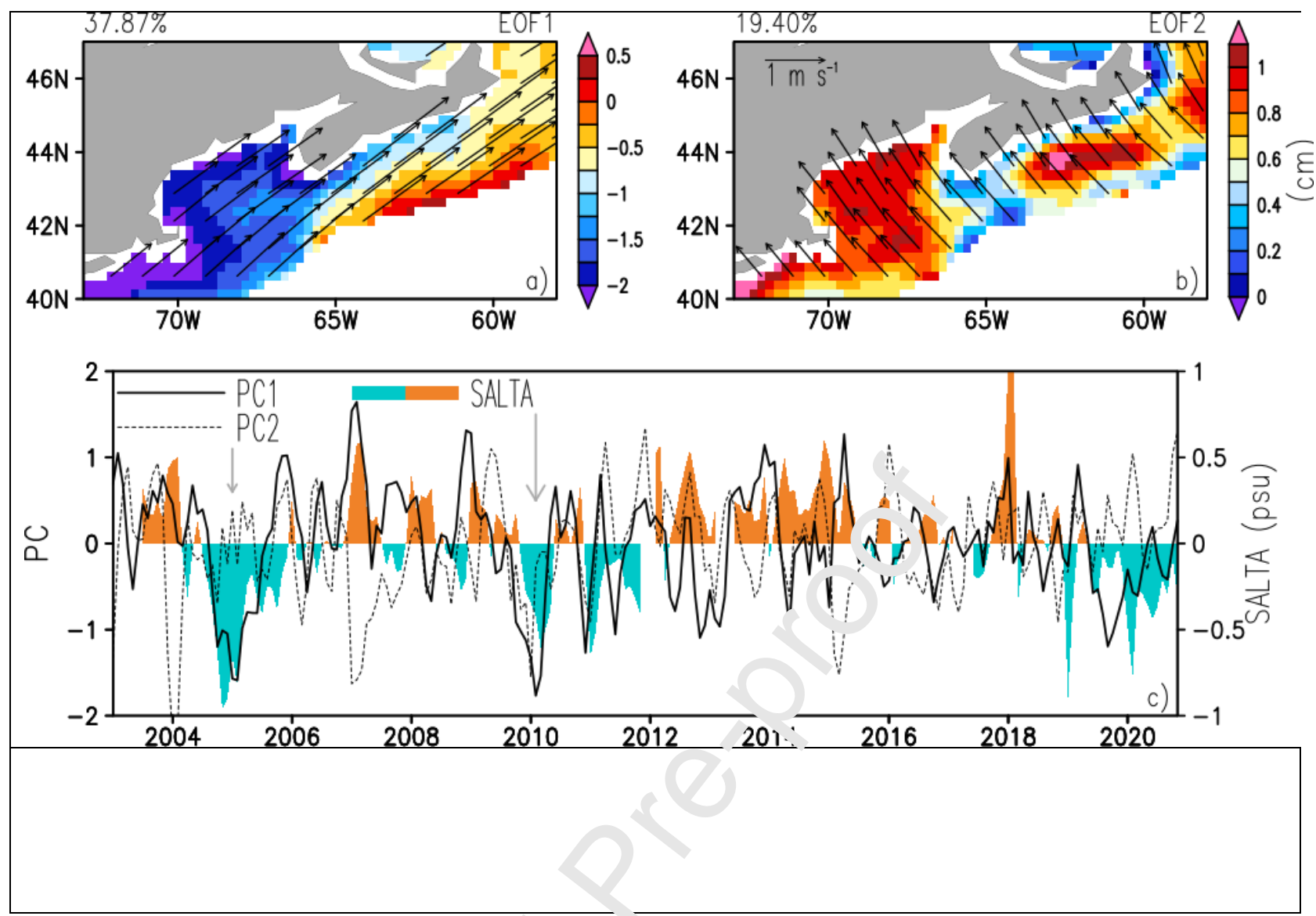

Figure 7. Two leading multivariate EG's of de-trended absolute dynamics topography and winds: (a, b) spatial patterns, (, or esponding temporal principal components (PC), with Gulf of Maine salinity anomaiy ir , m buoy M01 (SALTA) included. Arrows in (c) show sample fresh events that ar: $\operatorname{ex}_{1}$ 'lained by negative PC1 episodes.

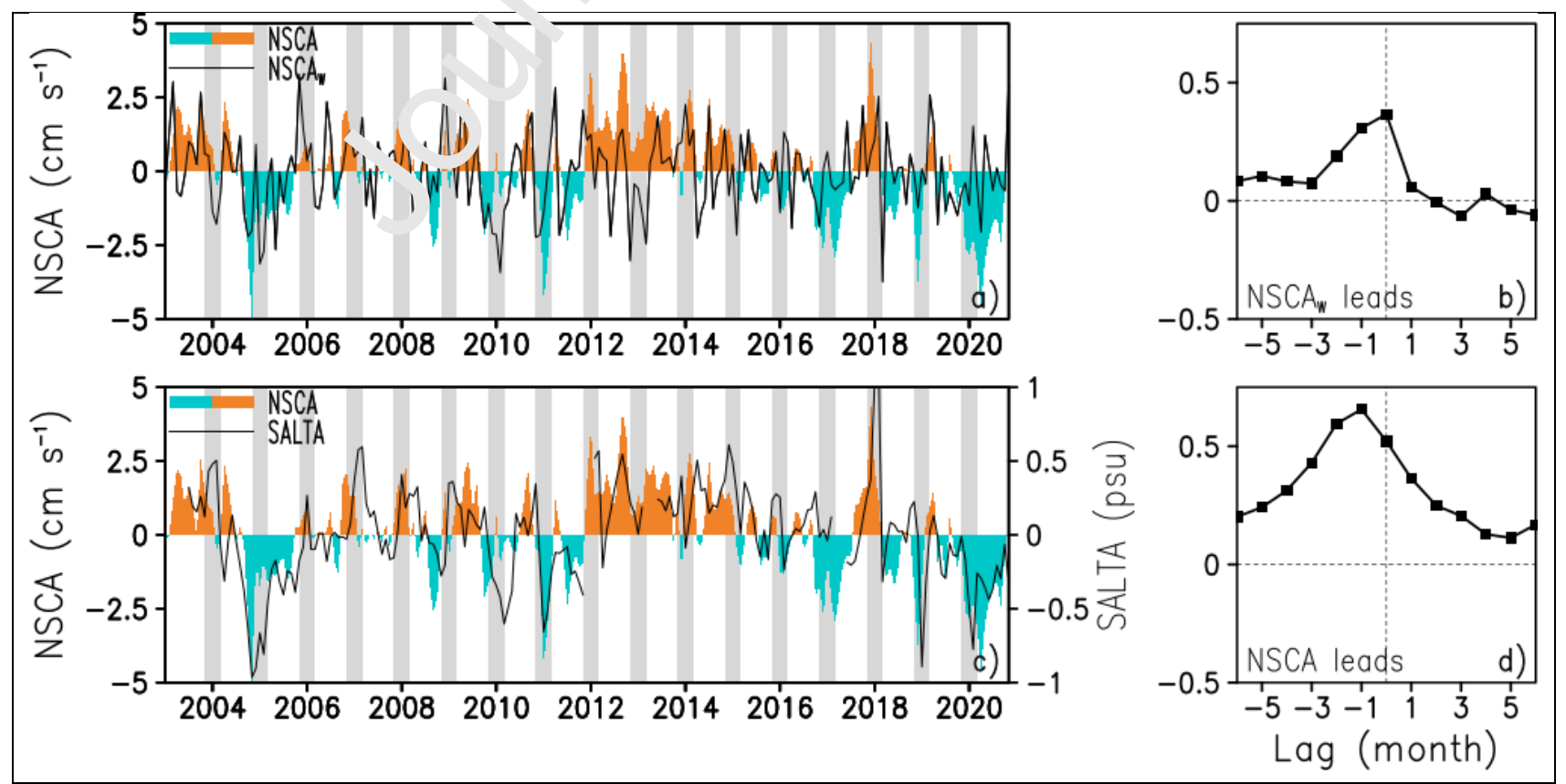


Figure 8. (a) Time series of Nova Scotia Current geostrophic velocity anomaly (NSCA, positive - northeastward) averaged over the Scotian Shelf index area (Fig. 2a) and its wind-driven component evaluated from the two leading EOF modes (Fig. 7, NSCA ${ }_{W}$; b) their lagged correlation. (c) NSCA and 0-20m mean salinity anomaly (SALTA) from mooring M01, (d) their lagged correlation. Winter period (November-February) of each year is shaded grey in $(\mathrm{a}, \mathrm{c})$.
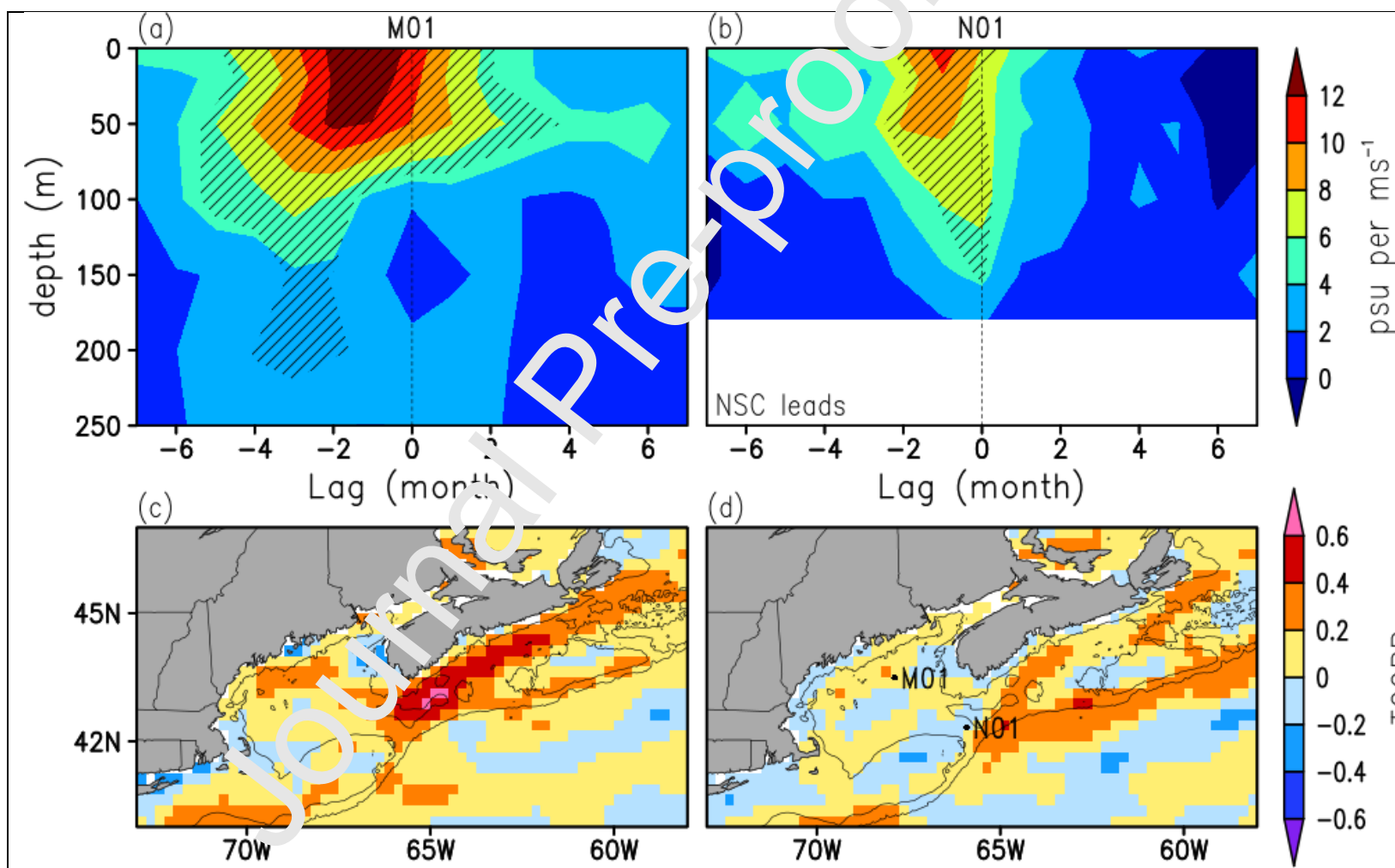

Figure 9. Lagged regression of NSCA with anomalous salinity (SALTA) at moorings (a) M01 and (b) N01, STD(NSCA) $=0.015 \mathrm{~m} \mathrm{~s}^{-1}, 99 \%$ statistically significant correlations are hatched. Temporal correlation (TCORR) of 0-20m monthly-averaged (c) M01 and (d) N01 SALTA with previous month altimeter-derived alongshore geostrophic velocity anomaly elsewhere. Mooring locations are shown in (d). 100 and 1000-m depth contours are shown in (c, d).

Figure 10. (a) Monthly SMAP sea surface salinity anomaly (SSSA) averaged over the eastern GoM index area (eGoM, bars) and mooring site M01 SSSA. (b) Scatter plot of winter (November-February) eGoM SSSA against 1-month leading alongshore Nova Scotia wind anomaly, $U a(t-1)$, and their linear regression fit. (c) A calculated residual 
removing the alongshore fit, $\Delta \mathrm{SSSA}=\mathrm{eGoM}-0.37 * U a(t-1)$, versus 1 -month leading cross-shore wind anomaly. Small red open circles in (a) show months illustrated in Fig. 4.

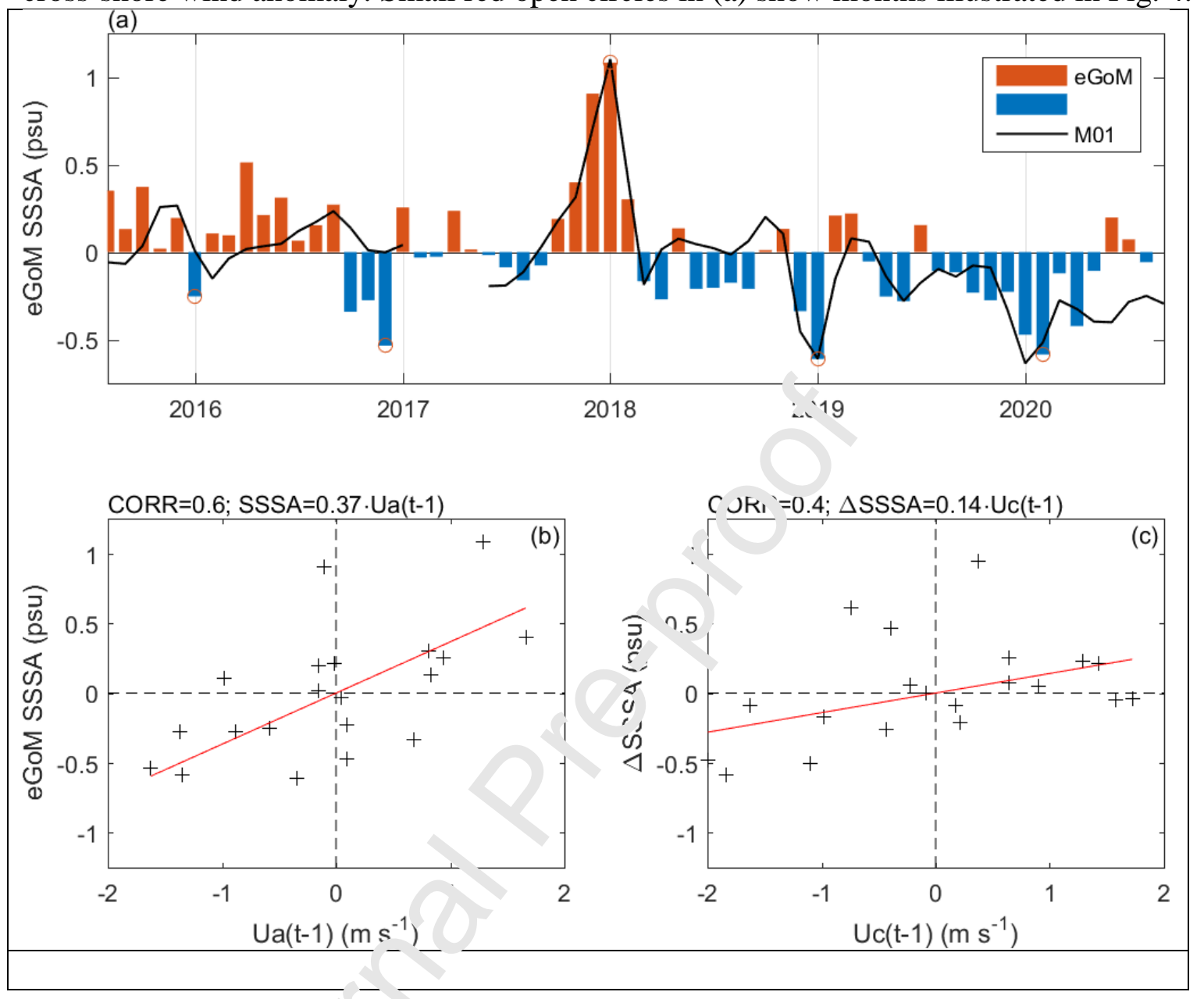




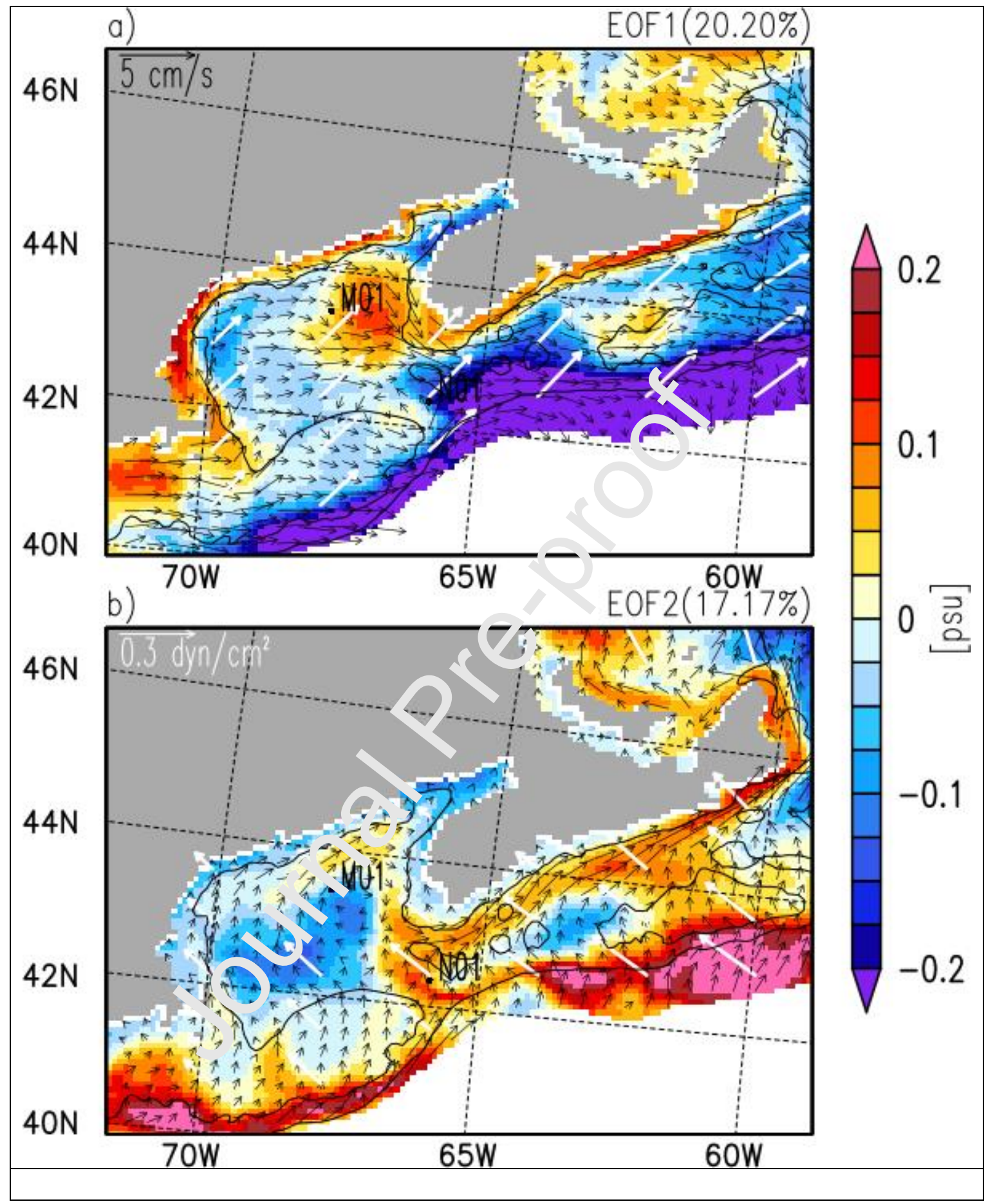

Figure 11. The two leading modes of multivariate EOF analysis of surface salinity (shading), currents (black arrows), and wind stress (white arrows) based on POP2 eddyresolving 19-year $0.1^{0}$ global simulations driven by interannually varying atmospheric forcing and climatological river discharge. NERACOOS mooring M01 and N01 locations are shown. Depth contours (100m and 1000m) are shown in solid black. 


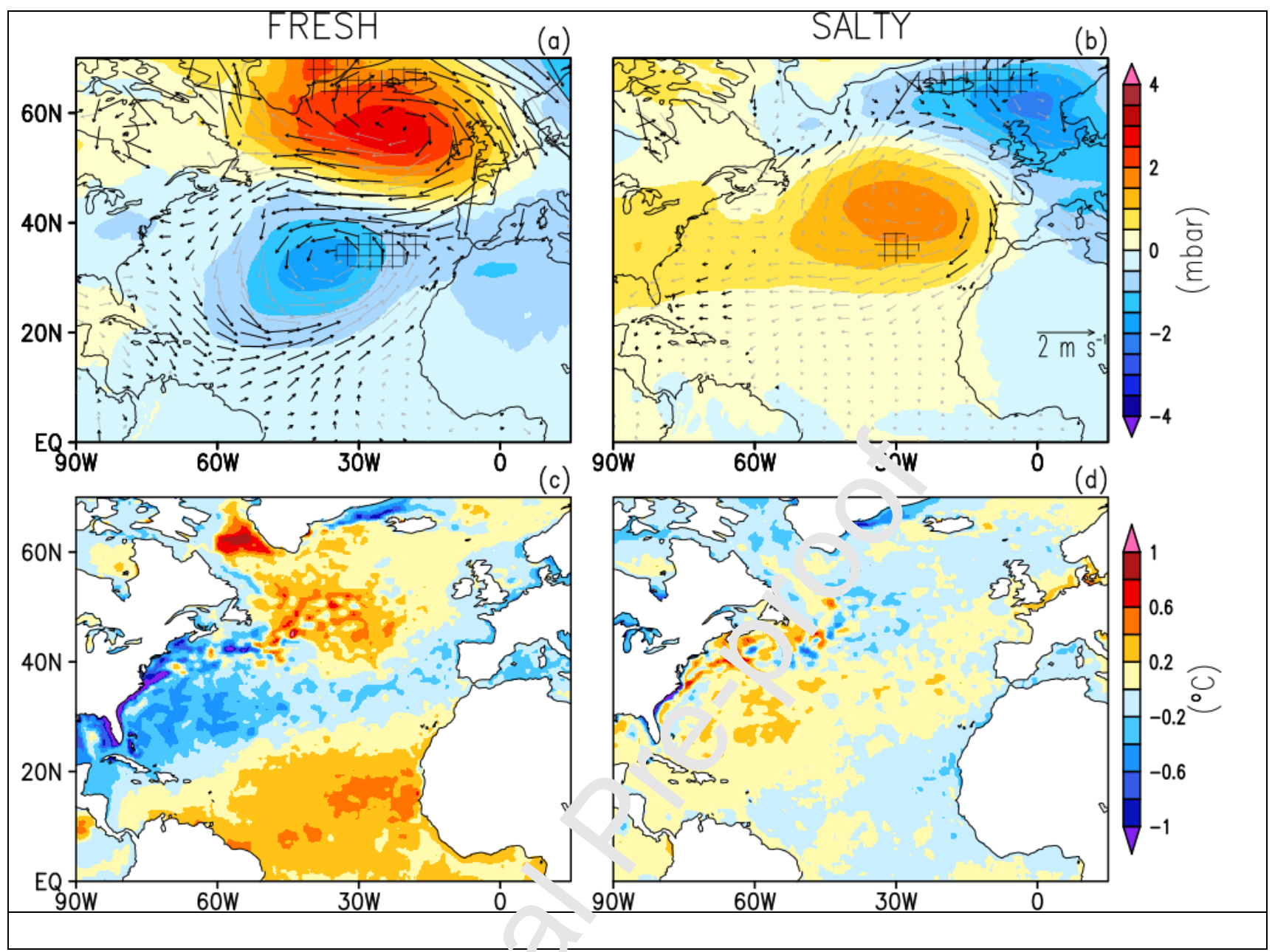

Figure 12. Basin-scale surface atm $v_{n}$ hlinit anomalies composited for winter months with strong $(a, c)$ fresh or $(b, d)$ salty SSSA at m -oring M01. Top panels $(a, b)$ show MSLP (shaded) and wind (arrows) anomaly composites. Bu. ${ }^{+}$om panels (c,d) show de-trended SST anomaly composites. Hatching illustrates Azores $\mathrm{i}: \mathrm{gh}$, nd Icelandic low positions for (a) negative and (b) positive winter NAO. Black arrov s $1 \mathrm{l}(\mathrm{a}, \mathrm{b})$ correspond to areas where the temporal correlation of anomalous winds with . nu.i.ing M01 SSSA is statistically significant at the 95\% level. A strong SSSA event is defined as : ny month within the November-March period where $|\mathrm{SSSA}|$ exceeds $50 \%$ of its STD.

\section{Highlights}

- SMAP detects significant eastern GoM SSSA (up to 1 psu) in four of five winters.

- Jordan basin SSSA correlation with Nova Scotia Current geostrophic anomaly is $\sim 0.7$.

- Only half of the above correlation is explained by wind-driven current variations.

- Eastern GoM satellite SSSA index is better indicator of fresh Scotian Shelf inflows. 